\title{
Acute and Persistent Withdrawal Syndromes Following Discontinuation of Psychotropic Medications
}

\author{
Fiammetta $\operatorname{Cosci}^{a, b}$ Guy Chouinard ${ }^{c}$

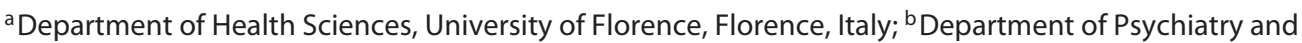 \\ Neuropsychology, Maastricht University, Maastricht, The Netherlands; ${ }^{C}$ Clinical Pharmacology and Toxicology \\ Program, McGill University and Mental Health Institute of Montreal Fernand Seguin Research Centre, University of \\ Montreal, Montreal, QC, Canada
}

\author{
Keywords \\ Withdrawal · Discontinuation · Selective serotonin reuptake \\ inhibitor · Serotonin noradrenaline reuptake inhibitor · \\ Benzodiazepine · Antipsychotic · Lithium · Mood stabilizers · \\ Antidepressant $\cdot$ Tolerance
}

\begin{abstract}
Studies on psychotropic medications decrease, discontinuation, or switch have uncovered withdrawal syndromes. The present overview aimed at analyzing the literature to illustrate withdrawal after decrease, discontinuation, or switch of psychotropic medications based on the drug class (i.e., benzodiazepines, nonbenzodiazepine benzodiazepine receptor agonists, antidepressants, ketamine, antipsychotics, lithium, mood stabilizers) according to the diagnostic criteria of Chouinard and Chouinard [Psychother Psychosom. 2015;84 (2):63-71], which encompass new withdrawal symptoms, rebound symptoms, and persistent post-withdrawal disorders. All these drugs may induce withdrawal syndromes and rebound upon discontinuation, even with slow tapering. However, only selective serotonin reuptake inhibitors, serotonin noradrenaline reuptake inhibitors, and antipsychotics were consistently also associated with persistent post-withdrawal disorders and potential high severity of symptoms, including
\end{abstract}

alterations of clinical course, whereas the distress associated with benzodiazepines discontinuation appears to be shortlived. As a result, the common belief that benzodiazepines should be substituted by medications that cause less dependence such as antidepressants and antipsychotics runs counter the available literature. Ketamine, and probably its derivatives, may be classified as at high risk for dependence and addiction. Because of the lag phase that has taken place between the introduction of a drug into the market and the description of withdrawal symptoms, caution is needed with the use of newer antidepressants and antipsychotics. Within medication classes, alprazolam, lorazepam, triazolam, paroxetine, venlafaxine, fluphenazine, perphenazine, clozapine, and quetiapine are more likely to induce withdrawal. The likelihood of withdrawal manifestations that may be severe and persistent should thus be taken into account in clinical practice and also in children and adolescents.

(c) 2020 S. Karger AG, Basel

\section{Introduction}

Psychotropic drugs may cause withdrawal reactions which can occur after abrupt discontinuation or gradual tapering [1] with a prevalence of $54 \%$ among adults with karger@karger.com

(c) 2020 S. Karger AG, Basel

www.karger.com/pps

Karger ${ }^{\prime}=$
Fiammetta Cosci

Department of Health Sciences, University of Florence

Via di San Salvi, 12

IT-50135 Florence (Italy)

fiammetta.cosci@unifi.it 
Table 1. New withdrawal symptoms following decrease, discontinuation, or switch of psychotropic medications

\begin{tabular}{|c|c|}
\hline Type & New withdrawal symptoms \\
\hline Course & Transient \\
\hline Duration & Up to 6 weeks (depending on drug elimination half-life) \\
\hline Outcome & Reversible, with complete recovery \\
\hline Diagnostic criteria & $\begin{array}{l}\text { (A) Dose decrease, discontinuation, or switch of a psychotropic medications } \\
\text { (B) Rapid appearance of at least } 2 \text { new symptoms which might be unspecific or specific for the psychotro- } \\
\text { pic medication class } \\
\text { (C) Symptoms in criteria B are characterized by a peak of onset within } 36-96 \mathrm{~h} \text { after decrease, discontinu- } \\
\text { ation, or switch of a psychotropic medication (depending on drug duration of action) and last for up to } 6 \\
\text { weeks (depending on drug elimination half-life) } \\
\text { (D) Symptoms in criteria B cause clinically significant distress } \\
\text { (E) Symptoms in criteria B are not due to a general medical condition and are not better accounted for by } \\
\text { another mental disorder or substance use }\end{array}$ \\
\hline
\end{tabular}

a diagnosis of serious mental illness [2]. A recent review of the literature suggested that benzodiazepines, Z-drugs, ketamine, selective serotonin reuptake inhibitors (SSRIs), serotonin-norepinephrine reuptake inhibitors (SNRIs), tricyclic antidepressants (TCAs), antipsychotics, monoamine oxidase inhibitors (MAOIs), and gabapentin are associated with withdrawal symptoms [3]. Thus, it confirmed what was previously reported in reviews focusing on specific drug classes [4-9]. Regarding SSRIs and SNRIs, the term "discontinuation syndrome" had been used for several years. However, this definition is no longer accepted; the term "withdrawal syndrome" is more appropriate and there are no reasons to believe that there are differences from other classes of psychotropic drugs $[3-5,7,10]$.

Based on the literature, Chouinard and Chouinard proposed in 2015 [10] 3 types of withdrawal syndromes for psychotropic medications: new withdrawal symptoms $[5,11-16]$, rebound symptoms $[1,13,14,17-20]$, and persistent post-withdrawal disorders $[21,22]$ (Tables 1-3). First, new withdrawal symptoms (Table 1) are usually short-lasting, transient, reversible symptoms, which are new to the patient. New symptoms are usually the same, common to all psychotropic medications during withdrawal $[12,15,23]$ (e.g., nausea, headaches, sleep disturbances) [10], but also specific and unique for a drug class (e.g., specific serotonin-related symptoms: flu-like symptoms, diarrhea, confusion) [10]. Second, rebound symptoms (Table 2) are short-lasting, transient, revers- ible symptoms which represent a rapid return of the primary symptoms usually at a greater intensity than before treatment $[13,14]$. Third, persistent post-withdrawal disorders (Table 3) are a set of long-lasting, severe, potentially irreversible symptoms [10] which entitle rebound primary symptoms or primary disorder at greater intensity and/or new withdrawal symptoms and/or new symptoms or disorders that were not present before treatment. They persist $>6$ weeks.

Withdrawal from psychotropic medications can produce psychiatric symptoms often confounded with relapse (i.e., a return of the same episode) or recurrence (i.e., a new episode) of the original illness [10]. However, both relapse and recurrence have 2 clinical features different from withdrawal syndromes: (1) the gradual onset of the original symptoms and illness, while drug withdrawal produces acute, abrupt return; (2) symptom severity as before drug treatment, while drug withdrawal produces greater severity [10]. On the other hand, Fava et al. [24] suggested that withdrawal from psychotropic medications can be associated with modifications of the illness course such as switching to mania as well as other forms of tolerance [24] such as loss of antidepressant clinical effects [25], resistance when the same medication is administered again [26], and general refractoriness to treatment $[25,27,28]$.

The aim of the present overview of the literature was to apply the use of the diagnostic criteria proposed by Chouinard and Chouinard [10] to illustrate withdrawal 
Table 2. Rebound symptoms following decrease, discontinuation, or switch of psychotropic medications

\begin{tabular}{ll}
\hline Type & Rebound symptoms \\
\hline Peak of onset & $36-96$ h (or later depending on drug duration of action) \\
\hline Course & Transient \\
\hline Duration & Up to 6 weeks (depending on drug elimination half-life) \\
\hline Outcome & Reversible, with complete recovery \\
\hline Clinical manifestations & Return of the original symptoms at a greater intensity than before treatment \\
\hline Diagnostic criteria & $\begin{array}{l}\text { (A) Dose decrease, discontinuation, or switch of a psychotropic medication } \\
\text { (B) Rapid return of original symptoms at a greater intensity than before treatment } \\
\text { (C) Symptoms in criteria B are characterized by a peak of onset within 36-96 h after decrease, discon- } \\
\text { tinuation, or switch of a psychotropic medication (depending on drug duration of action) and last for } \\
\text { up to 6 weeks (depending on drug elimination half-life) } \\
\text { (D) Symptoms in criteria B cause clinically significant distress } \\
\text { (E) Symptoms in criteria B are not due to a general medical condition and are not better accounted for } \\
\text { by another mental disorder or substance use }\end{array}$ \\
\hline
\end{tabular}

Table 3. Persistent post-withdrawal disorder following decrease, discontinuation, or switch of psychotropic medications

\begin{tabular}{ll}
\hline Type & Persistent post-withdrawal disorder \\
\hline Peak of onset & 24 h to 6 week (or later depending on drug duration of action) \\
\hline Course & Persistent \\
\hline Duration & More than 6 weeks (depending on drug elimination half-life) \\
\hline Outcome & Potentially irreversible \\
\hline Diagnical manifestations criteria & $\begin{array}{l}\text { Return of original symptoms at greater intensity and/or new withdrawal symptoms that persist over } 6 \\
\text { weeks and/or appearance of new symptoms that were not present before }\end{array}$ \\
& $\begin{array}{l}\text { (A) Dose decrease, discontinuation, or switch of a psychotropic medication } \\
\text { (B) Rapid return of original symptoms at a greater intensity than before treatment and/or rapid appear- } \\
\text { ance of new withdrawal symptoms which can be unspecific or specific for the psychotropic medication } \\
\text { class } \\
\text { (C) Symptoms in criteria B are characterized by a peak of onset within 24 h and } 6 \text { weeks after decrease, } \\
\text { discontinuation, or switch of a psychotropic medication (depending on drug duration of action), and last } \\
\text { more than } 6 \text { weeks (depending on drug elimination half-life) } \\
\text { (D) Symptoms in criteria B cause clinically significant distress } \\
\text { (E) Symptoms in criteria B are not due to a general medical condition and are not better accounted for by } \\
\text { another mental disorder or substance use }\end{array}$ \\
\hline
\end{tabular}

after decrease, discontinuation, or switch of psychotropic medications based on the drug class (i.e., benzodiazepines, nonbenzodiazepine benzodiazepine receptor agonists, antidepressants, ketamine, antipsychotics, lithium, mood stabilizers) and different molecules. The ultimate purpose is to organize the data in a clinically useful way.

Withdrawal Syndromes

\section{Methods}

Eligible articles included papers in English published in peer-review journals reporting data on adult subjects who decreased, discontinued, or switched psychotropic medications.

MEDLINE was comprehensively searched from inception to January 2020. In addition, a manual search of reference lists from all articles selected, for full-text re- 
views, and relevant reviews were done. Search terms were "discontinuation/withdrawal," combined using the Boolean "AND" operator with "benzodiazepine/nonbenzodiazepine benzodiazepine receptor agonist/Z-drug/antidepressant/ketamine/esketamine/antipsychotic/neuroleptic/lithium/mood stabilizer."

Titles and abstracts were screened by 1 reviewer (F.C.). Articles appearing potentially relevant were retrieved and 2 reviewers (F.C. and G.C.) independently assessed each of the full reports, arriving at consensus regarding eligibility.

When information about the methods or results was omitted, the writers of the report were contacted to obtain the missing information. In case of the suspect of duplicate publications, the authors of the reports were contacted to receive further details.

Since new withdrawal symptoms have been described in the literature in several ways and using different words, a categorization used previously for antidepressant discontinuation symptoms $[5,6,10]$ was adopted. It includes general symptoms; cardiovascular symptoms; gastrointestinal symptoms; genitourinary symptoms; sensory-related symptoms; neuro-muscular symptoms; sexual symptoms; central nervous system symptoms (which were articulated as: neurological, cognitive, affective, psychotic, behavioral, sleep-related symptoms).

\section{Benzodiazepines and Nonbenzodiazepine Benzodiazepine Receptor Agonists}

The first systematic review on withdrawal symptoms associated with benzodiazepine discontinuation was published in 1980 by the Committee on the Review of Medicines [29]. Interestingly, they concluded that the true addiction potential of benzodiazepines was low, since a dependence rate of $5-10$ cases per million patient months was estimated [30]. Such cases of addiction were more frequent in drug misusers. Few reports described dependence during medically supervised treatment which occurred when high doses were used for extended periods [29].

As for nonbenzodiazepine benzodiazepine receptor agonists (i.e., eszopiclone, zaleplon, zolpidem, zopiclone), or Z-drugs, when they are discontinued, patients also report new withdrawal and rebound symptoms. Based on our review of what has been published in the literature, we found: (1) one report of eszopiclone cessation produced new withdrawal symptoms (i.e., abnormal dreams, nausea, upset stomach) and rebound anxiety [31]; (2) two reports of abrupt discontinuation of zolpidem were associated with rebound insomnia [32, 33]; (3) three reports of 2 cases of zolpidem withdrawal seizure were described [34, 35]; (4) zopiclone, the S-isomer of eszopiclone, was found to induce daytime inter-dose rebound anxiety [36]. There is no reason to believe that Z-drugs are any different than benzodiazepines. Short-acting and short elimination half-life Z-drugs with high potency are predicted to be similar to their benzodiazepine counterpart to produce withdrawal symptoms. Up to now, no data on persistent post-withdrawal disorders are published for Zdrugs. Apparently, little is still known on these recently marketed molecules, and no studies evaluated how to manage withdrawal syndromes after their decrease or discontinuation. Published data so far have been linked directly or indirectly with pharmaceutical companies.

\section{New Withdrawal Symptoms after Benzodiazepine}

\section{Discontinuation}

Benzodiazepine discontinuation is known to produce minor as well as major new withdrawal symptoms. Table 4 reports most frequent minor new withdrawal symptoms [37-41], among them sweating, tachycardia, nausea, visual changes, tremor, confusion, restlessness. Major withdrawal symptoms, such as seizure $[42,43]$ and psychosis [43], are rare. Seizure usually occurs in predisposed subjects (i.e., history of brain damage, alcohol addiction, abnormal electroencephalograms) [44] or in those treated with drugs which lower the seizure threshold (i.e., TCAs, bupropion, antipsychotics) [45].

New withdrawal symptoms are generally mild, transient, and subside within 2-4 weeks [46, 47]. They appear more frequently [37, 44, 48] and are more severe [49] with high-potency benzodiazepines with short to medium elimination half-life. More new withdrawal symptoms were found upon discontinuation of lorazepam (high potency and short-acting) than with diazepam [38]. Elimination rates of benzodiazepines also predict the time of onset [15] of new withdrawal symptoms: after discontinuation of rapidly eliminated benzodiazepines (i.e., lorazepam, oxazepam) [50], new withdrawal symptoms occurred within $48 \mathrm{~h}$; with slowly eliminated benzodiazepine (i.e., diazepam) new withdrawal symptoms occurred after 5 days with peak severity after 9.6 days. However, $75 \%$ of patients who withdrawn after long-term use of benzodiazepines developed new withdrawal symptoms regardless of rapidly eliminated or slowly eliminated compounds [51].

In the 12-year Luxemburg study ( $n=214,170$ subjects), all available hypnotics (including triazolam) and 
Table 4. New withdrawal symptoms after decrease or discontinuation of psychotropic medications

\begin{tabular}{|c|c|c|c|c|c|c|}
\hline System involved & Benzodiazepines & $\begin{array}{l}\text { Nonbenzodiazepine } \\
\text { benzodiazepine } \\
\text { receptor agonists }\end{array}$ & SSRI/SNRI & $\begin{array}{l}\text { Tricyclics, MAOIs, other } \\
\text { antidepressants }\end{array}$ & Antipsychotics & Mood stabilizers \\
\hline \multirow[t]{16}{*}{ General } & Sweating & & Sweating & Sweating & Sweating & Sweating \\
\hline & Flu-like symptoms & & Flu-like symptoms & Flu-like symptoms & Flu-like symptoms & $\begin{array}{l}\text { Flu-like } \\
\text { symptoms }\end{array}$ \\
\hline & Headache & & Headache & Headache & Headache & Headache \\
\hline & Flushing & & $\begin{array}{l}\text { Flushing } \\
\text { Chills }\end{array}$ & Chills & Chills & \\
\hline & Fatigue & & Fatigue & Fatigue & & \\
\hline & Weakness & & Weakness & & & Weakness \\
\hline & Pain & & Pain & & & Pain \\
\hline & Malaise & & Malaise & & & \\
\hline & Perceptual ataxia & & & & & \\
\hline & Itching, skin rash & & & & & \\
\hline & & & Tiredness & & & \\
\hline & & & Lethargy & & & \\
\hline & & & Infection & & & \\
\hline & & & & & Hypothermia & \\
\hline & & & & Dizziness & & Dizziness \\
\hline & & & & Lacrimation & & \\
\hline \multirow[t]{12}{*}{ Cardiovascular } & Tachycardia & & Tachycardia & Tachycardia & Tachycardia & Tachycardia \\
\hline & Dizziness & & Dizziness & & Dizziness & \\
\hline & Lightheadedness, vertigo & & Lightheadedness & & Lightheadedness & \\
\hline & Chest pain & & Chest pain & & Chest pain & \\
\hline & & & Hypertension & & Hypertension & Hypertension \\
\hline & Postural hypotension & & Postural hypotension & & & Hypotension \\
\hline & & & Vertigo & & & \\
\hline & & & Syncope & & Pre-syncope & \\
\hline & & & Dyspnea & & & \\
\hline & & & & & Angina pectoris & \\
\hline & & & & & Risk of myocardial infarction & \\
\hline & & & & Arrhythmia & & \\
\hline \multirow[t]{12}{*}{ Gastrointestinal } & Nausea & Nausea & Nausea & Nausea & Nausea & Nausea \\
\hline & Vomiting & & Vomiting & Vomiting & Vomiting & Vomiting \\
\hline & Anorexia, weight loss & & $\begin{array}{l}\text { Anorexia, appetite } \\
\text { problems }\end{array}$ & Low appetite & Anorexia & Anorexia \\
\hline & Diarrhea & & Diarrhea & Diarrhea & Diarrhea & \\
\hline & Abdominal pain/cramp & & $\begin{array}{l}\text { Abdominal pain/cramp/ } \\
\text { distention }\end{array}$ & & Abdominal pain/cramp & \\
\hline & & & Loose stools & & Loose stools & \\
\hline & & & & & Salivation & \\
\hline & & & Esophagitis & & & \\
\hline & & & $\begin{array}{l}\text { Increased bowel } \\
\text { movements }\end{array}$ & & & \\
\hline & Constipation & & & & & \\
\hline & Dry mouth & & & & & \\
\hline & $\begin{array}{l}\text { Gastrointestinal } \\
\text { problems }\end{array}$ & Gastric problems & & Gastrointestinal problems & & $\begin{array}{l}\text { Gastrointestinal } \\
\text { problems }\end{array}$ \\
\hline
\end{tabular}


Table 4 (continued)

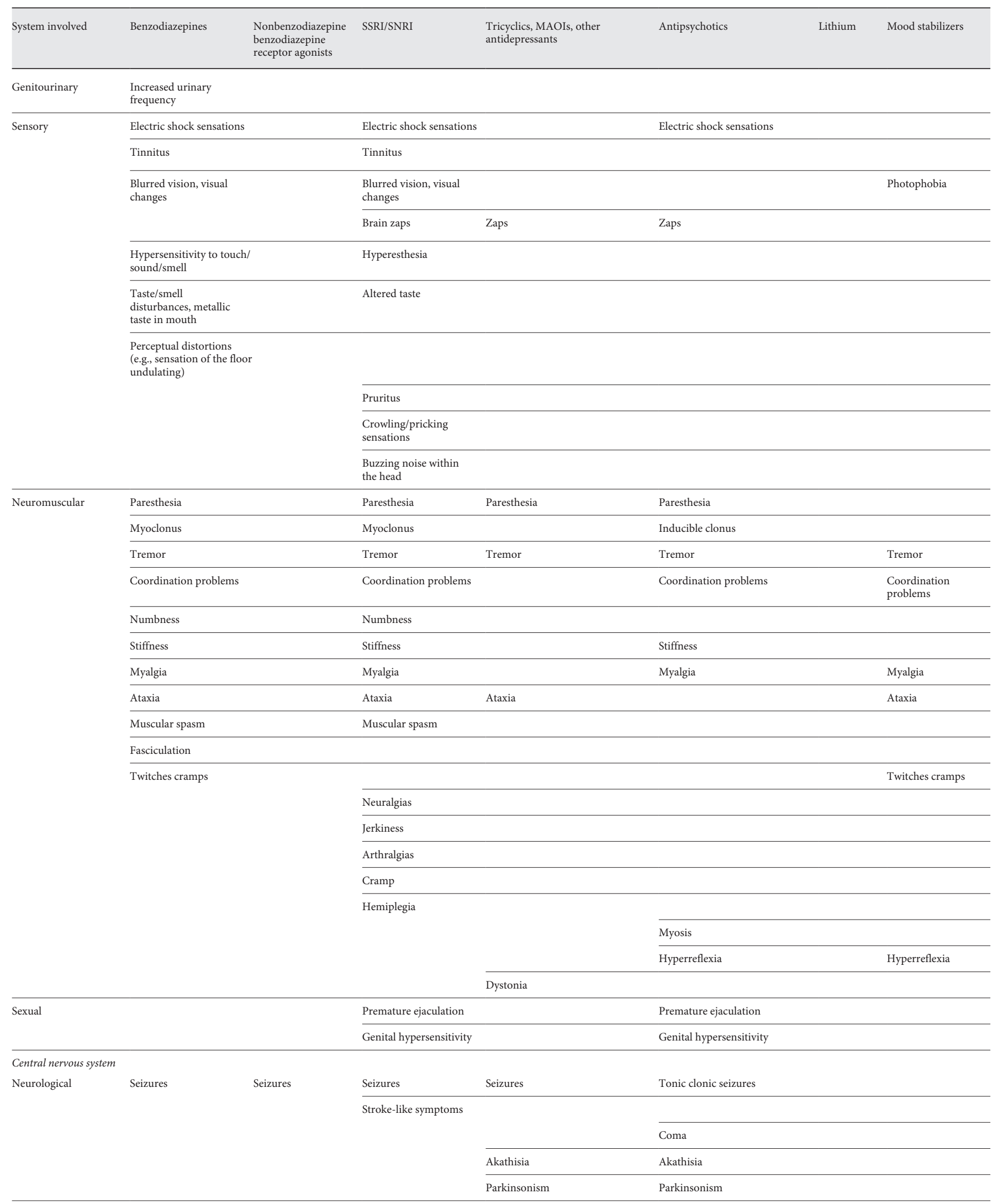


Table 4 (continued)

\begin{tabular}{|c|c|c|c|c|c|c|c|}
\hline System involved & Benzodiazepines & $\begin{array}{l}\text { Nonbenzodiazepine } \\
\text { benzodiazepine } \\
\text { receptor agonists }\end{array}$ & SSRI/SNRI & $\begin{array}{l}\text { Tricyclics, MAOIs, other } \\
\text { antidepressants }\end{array}$ & Antipsychotics & Lithium & Mood stabilizers \\
\hline \multirow[t]{8}{*}{ Cognitive } & Confusion & & Confusion & & Confusion & & Confusion \\
\hline & Amnesia & & Amnesia & & Amnesia & & Ipomnesia \\
\hline & \multirow{2}{*}{\multicolumn{2}{|c|}{ Decreased concentration }} & \multicolumn{3}{|l|}{ Decreased concentration } & & $\begin{array}{l}\text { Decreased } \\
\text { concentration }\end{array}$ \\
\hline & & & Disorientation & & Disorientation & & \\
\hline & \multirow{2}{*}{\multicolumn{2}{|c|}{ Lethargy }} & Lethargy, drowsiness & & Lethargy & & \\
\hline & & & Attention difficulties & & Attention difficulties & & \\
\hline & \multicolumn{7}{|l|}{ Indecision } \\
\hline & & & Slurred speech & & & & \\
\hline \multirow[t]{19}{*}{ Affective } & Anxiety & & Anxiety & Anxiety & Anxiety & Anxiety & Anxiety \\
\hline & Agitation & & Agitation & Agitation & Agitation & & Agitation \\
\hline & Depression & & Depression & Depression & Depression & & Depression \\
\hline & Irritability & & Irritability & Irritability & Irritability & Irritability & Irritability \\
\hline & Panic & & Panic & Panic & & & \\
\hline & Derealization & & Derealization & & & & \\
\hline & Depersonalization & & Depersonalization & Depersonalization & & & Depersonalization \\
\hline & \multirow{6}{*}{\multicolumn{2}{|c|}{ Dysphoria }} & Dysphoria & Dysphoria & Dysphoria & & Dysphoria \\
\hline & & & Mood swings & & & & \\
\hline & & & Suicidal ideation & & & & \\
\hline & & & $\begin{array}{l}\text { Hypomania, } \\
\text { euphoria }\end{array}$ & Hypomania, mania & & & \\
\hline & & & & & & & Anhedonia \\
\hline & & & Fear & & & & \\
\hline & \multirow{3}{*}{\multicolumn{2}{|c|}{ Nervousness }} & Nervousness & & & & \\
\hline & & & Tension & & & & Tension \\
\hline & & & Anger & & & & \\
\hline & \multicolumn{7}{|l|}{ Feeling of imminent death } \\
\hline & \multicolumn{7}{|l|}{ Terror } \\
\hline & \multicolumn{7}{|l|}{ Agoraphobia } \\
\hline \multirow[t]{7}{*}{ Psychotic } & Hallucinations & & $\begin{array}{l}\text { Visual/auditory } \\
\text { hallucinations }\end{array}$ & Hallucinations & & & Hallucinations \\
\hline & \multirow{2}{*}{\multicolumn{2}{|c|}{ Delirium }} & \multicolumn{5}{|l|}{ Delirium } \\
\hline & & & Catatonia & & Catatonia & & \\
\hline & Paranoia & & & Paranoia & & & Paranoia \\
\hline & \multicolumn{7}{|l|}{ Distortion of body image } \\
\hline & \multicolumn{7}{|l|}{ Psychosis } \\
\hline & & & & Delusions & & & \\
\hline \multirow[t]{4}{*}{ Behavioral } & Restlessness & & Restlessness & Restlessness & Restlessness & & \\
\hline & \multirow{3}{*}{\multicolumn{2}{|c|}{ Aggressive behavior }} & Aggressive behavior & & Aggressive behavior & & \\
\hline & & & Impulsivity & & & & \\
\hline & & & $\begin{array}{l}\text { Bouts of crying/outbursts } \\
\text { of anger }\end{array}$ & & & & \\
\hline
\end{tabular}


Table 4 (continued)

\begin{tabular}{|c|c|c|c|c|c|c|c|}
\hline System involved & Benzodiazepines & $\begin{array}{l}\text { Nonbenzodiazepine } \\
\text { benzodiazepine } \\
\text { receptor agonists }\end{array}$ & SSRI/SNRI & $\begin{array}{l}\text { Tricyclics, MAOIs, other } \\
\text { antidepressants }\end{array}$ & Antipsychotics & Lithium & Mood stabilizers \\
\hline \multirow[t]{5}{*}{ Sleep } & Insomnia & & Insomnia & Insomnia & Insomnia & & Insomnia \\
\hline & Nightmares & & Nightmares & Nightmares & & & \\
\hline & Sleep problems & & Sleep problems & Restless sleep & & $\begin{array}{l}\text { Sleep } \\
\text { problems }\end{array}$ & \\
\hline & & Abnormal dreams & Vivid dreams & Vivid frightening dreams & & & \\
\hline & & & Hypersomnia & & & & \\
\hline
\end{tabular}

SSRI, selective serotonin reuptake inhibitor; SNRI, serotonin noradrenaline reuptake inhibitor; MAOIs, monoamine oxidase inhibitors.

triazolo benzodiazepine, alprazolam, were found to be at higher risk of continuous and high-dose use. In contrast, anxiolytic benzodiazepines, in particular, clobazam and clonazepam, were found to be significantly less problematic having lower risk of high-dose use [52].

\section{Rebound Symptoms after Benzodiazepine \\ Discontinuation}

Kales et al. [17] first reported rebound insomnia upon abrupt cessation of a nightly single dose of benzodiazepines after short-term use. This was confirmed by other studies [53-59]. Rebound anxiety was also observed [1, $38,50]$. It is an acute return of pretreatment anxiety above baseline following benzodiazepine withdrawal, even after short-term use. The symptoms are transient but may last 3 weeks after drug cessation [20].

The prevalence of rebound insomnia was found to be significantly lower in all benzodiazepines compared to triazolam [52, 60-69] and was lower than that with triazolam. Thus, similarly to rebound anxiety, the risk seems related to benzodiazepine elimination half-life and potency $[20,23]$ and independent form the length of treatment [1].

Short and intermediate elimination half-life benzodiazepines are at a greater risk of rebound anxiety compared to long elimination half-life agents $[20,44,70]$. In a placebo-controlled double-blind study [1], abrupt withdrawal resulted in 7 cases of rebound anxiety: 5 of 7 (71.4\%) treated with bromazepam and 2 of 7 (28.6\%) treated with diazepam, bromazepam is a high potency benzodiazepine with intermediate elimination half-life, whereas diazepam is a medium potency benzodiazepine with long elimination half-life [14]. Rebound anxiety can also occur during ongoing treatment with rapidly eliminated benzodiazepines when their pharmacological effects decrease. For example, increased daytime anxiety following a bedtime dose of triazolam [71], daytime interdose rebound anxiety in triazolam- and zopiclone-treated patients for insomnia in generalized anxiety disorder [36], clock-watching rebound anxiety $3-4 \mathrm{~h}$ after the last dose in lorazepam- and alprazolam-treated panic disorder patients [72].

Clonazepam [73-76] has a long elimination half-life, induced less frequently rebound anxiety than alprazolam [77].

\section{Persistent Post-Withdrawal Disorders after \\ Benzodiazepine Discontinuation}

The literature on persistent post-withdrawal disorders after long-term benzodiazepine use and discontinuation is hardly existent. Notwithstanding this, anxiety, depression, psychosis, cognitive impairment, insomnia, sensory phenomena (i.e., tinnitus, tingling, numbness, paresthesia, deep or burning pain in limbs, feeling of inner trembling or vibration, strange skin sensations), motor phenomena (i.e., muscle pain, weakness, painful cramps, tremor, jerks, spasms, shaking attacks), and gastrointestinal disturbances (patients complain of food intolerance and gaseous abdominal distension) have been described [41]. Length of treatment and high potency with short to intermediate elimination half-life seem important to favor the occurrence of persistent post-withdrawal disorders [41]. It has been observed that withdrawal symptoms after discontinuation of low-dose benzodiazepine may take 6-12 months to subside completely [47] and in some cases they persist for years [41].

\section{Associated Clinical Manifestations}

We found no evidence in the literature for clinical symptoms or disorders associated to withdrawal due to benzodiazepine decrease or discontinuation. 
Management of Benzodiazepine Discontinuation

Slow tapering, often extending over a year or more, has been suggested to manage new withdrawal symptoms [78]. However, even a more flexible tapering at a rate that the patient can tolerate, typically in about 3-6 months, has shown to be appropriate [37]. Some authors suggested tapering from other BZDs such as lorazepam after substituting diazepam [79], according to Murphy and Tyrer [80] such substitution has shown little evidence to support its efficacy.

The adjunct of cognitive behavioral therapy to a careful tapering schedule was found of limited value by Voshaar et al. [81], although 2 trials showed that cognitive behavioral therapy facilitated tapering among chronic benzodiazepine users $[82,83]$. In addition, it has been suggested that gradual discontinuation can reduce both rebound insomnia $[84,85]$ and rebound anxiety [1]. In contrast, in a randomized controlled trial evaluating the relative efficacy of 3 interventions for benzodiazepine discontinuation among panic disorder patients (i.e., taper alone, taper plus relaxation, and taper plus exposurebased cognitive-behavioral therapy), the rate of successful discontinuation of benzodiazepine treatment was significantly higher for those receiving the cognitive-behavioral program (13 of $17 ; 76 \%$ ) than for those receiving the slow taper program alone (4 of $16 ; 25 \%$ ); the results were confirmed at a 3-month follow-up [86]. These findings suggest that cognitive behavioral therapy may help benzodiazepine discontinuation. They were confirmed by Fava et al. [87] who observed an improvement in anxiety and anxiety sensitivity after stopping long-term benzodiazepines in patients who had recovered from panic disorder and agoraphobia after a successful behavioral treatment. However, when Otto et al. [86] attempted to replicate their own results published in 1993, the effect size was used instead of $p$ values, since significance levels did not allow to identify differences between groups, only the number of years of benzodiazepine use emerged as a significant predictor of benzodiazepine discontinuation in the regression models, only in the context of this single covariate the cognitive-behavioral therapy demonstrated significantly better outcome for benzodiazepine-free status than both relaxation and taper alone at 6-month follow-up [88].

On the other hand, we did not find studies which investigate strategies to manage benzodiazepine persistent post-withdrawal disorders.

\section{Antidepressants}

The literature indicates that antidepressant withdrawal reactions are frequent, with incidence rates ranging from 27 to $86 \%$ (weighted average of 56\%) [7]. Even though discontinuation symptoms were mostly reported after abrupt discontinuation, they were found to occur after gradual tapering $[5,6]$ and differ in prevalence according to the pharmacological profile of the antidepressant [89].

New withdrawal symptoms from TCAs were first reported with imipramine in 1959, described in 1961 [90], and later confirmed [91]. In 1980 and 1990s, Dilsaver documented general somatic and gastrointestinal distress; sleep disturbances characterized by initial and middle insomnia or excessively vivid and frightening dreams; akathisia or parkinsonism; hypomania or mania as manifestations of new withdrawal symptoms due to TCA discontinuation [92-95]. Cardiac arrhythmia rebound after discontinuation of imipramine was described [96] and persistent insomnia following discontinuation or decrease of amitriptyline documented $[13,14]$.

Following abrupt discontinuation of MAOIs, severe rebound panic was described [73] and subsequent studies reported that new withdrawal symptoms may occur [97]. Overall, TCAs and MAOIs aroused little interest [97], since withdrawal was seen in those days as part of a drug treatment necessary for the patient illness and a progress compared to previous treatments.

Case reports of new withdrawal symptoms (i.e., hypomania, anxiety, restless sleep, nightmares, depersonalization, formication, headache) after discontinuation of trazodone were published [98-101].

Among noradrenergic and specific serotonergic antidepressants (i.e., mirtazapine, mianserin, setiptiline), clinical case reports described new withdrawal symptoms (i.e., panic, anxiety, restlessness, irritability, hypomania, insomnia, dizziness, paresthesia, nausea, vomiting) and rebound mania after decrease or discontinuation of mirtazapine [102]. One case of seizure [103] and one case of panic attacks [104] were described after the abrupt discontinuation of mianserin, while no data were reported for setiptiline.

One study found acute dystonia as new withdrawal symptom resulting from abrupt discontinuation of bupropion [105].

The literature on the withdrawal of the more recently introduced antidepressants other than SSRI/SNRI is limited. The discontinuation of agomelatine was investigated in a 24-week randomized double-blind placebo-con- 
trolled study, after a brief 8- to 10-week open treatment [106]. The authors looked at adverse events "suggestive of withdrawal symptoms" within the first month after randomization in placebo-treated patients withdrawn from agomelatine. They found 3 emergent potentially withdrawal symptoms (i.e., depression, irritability, palpitations). However, they did not study withdrawal at the end of the 24-week randomized placebo-controlled study. In Stein et al. [107] and in Montgomery et al. [108], discontinuation symptoms in patients switched to placebo were similar to those of patients maintained on agomelatine.

No case reports after vilazodone or vortioxetine decrease or discontinuation are available. However, we should keep in mind that new antidepressants have a mechanism of action similar to that of first- and secondgeneration antidepressants. The difference is that they have new, or different, receptor targets, but the approach of looking for antidepressants which inhibit neurotransmitters reuptake is repeated [109]. Thus, future reviews of the literature might report more evidence on withdrawal syndromes after decrease or discontinuation of new antidepressants; this is likely because of their relatively recent release: the delay between the placing on the market of a drug and the publication of the first reports on adverse events is widely known for every new molecule.

SSRIs are the leading cause of withdrawal, followed by SNRIs [7]. The first systematic review of SSRIs withdrawal reactions was published in 2015 [5] and a few years later, Fava et al. [6] published the first systematic review on SNRIs.

\section{New Withdrawal Symptoms after SSRIs/SNRIs}

\section{Discontinuation}

New withdrawal symptoms following decrease or discontinuation of SSRIs have been widely documented and include a wide range of symptoms [5] which are listed in detail in Table 4.

Peaks of onset occur $36 \mathrm{~h}$ to 10 days after dose decrease or discontinuation, they are usually reversible and last from a few hours to 6 weeks $[5,16,97]$. Their frequency and duration depend on the drug discontinued $[5,16,97]$. A bulk of literature, derived from controlled trials [18, $110,111]$, case reports [19], and patients' online reports [112], showed that new withdrawal symptoms may occur with any type of SSRI, but paroxetine is the most likely to be associated with new symptoms, while fluoxetine being the least associated. Severity varies according to the SSRI, paroxetine being the most likely to be associated with severe depressive and somatic symptoms, and fluoxetine being the least likely to be associated with severe depressive and somatic symptoms $[5,111]$.

A systematic review of the literature [6] indicated that new withdrawal symptoms may occur also after discontinuation of SNRIs (i.e., venlafaxine, desvenlafaxine, duloxetine, milnacipran, levomilnacipran). Once again, new withdrawal symptoms include a wide range of clinical manifestations which are described in detail in Table 4. They occur irrespective of whether gradual or abrupt discontinuation is implemented and are similar to those observed after discontinuation of SSRIs [5]. They typically appear within a few days from drug discontinuation and last a few weeks. The prevalence of new withdrawal symptoms vary among the different drugs but was highest after the discontinuation of venlafaxine (rates of withdrawal from controlled trials and open trials rage from 23 to $78 \%$ ) and lowest after the discontinuation of levomilnacipran (rates of withdrawal from controlled trials and open trials rage from 9 to $10 \%$ ) [6].

\section{Rebound Symptoms after SSRIs/SNRIs \\ Discontinuation}

Controlled discontinuation studies [111, 113, 114] showed that rebound may occur following SSRI discontinuation. Rebound depression has been observed at a greater frequency with paroxetine or short-acting SSRIs $[10,13]$. In 2 double-blind placebo studies, patients with major depression had their maintenance medications (paroxetine, sertraline or fluoxetine) discontinued after 4-24 months and replaced with placebo and then reinstituted $[111,113]$. In one of the studies [111], patients taking paroxetine or sertraline had a sudden worsening of depressive symptoms upon drug discontinuation with a return to pre-placebo measurements following re-institution of the drug. In both studies $[111,113]$, patients treated with paroxetine had acute return of pre-treatment symptoms $[10,111,113]$, while patients taking fluoxetine did not.

Few studies also reported on rebound anxiety after venlafaxine discontinuation $[115,116]$.

\section{Persistent Post-Withdrawal Disorders after SSRIs/ SNRIs Discontinuation}

After SSRIs long-term use, persistent post-withdrawal disorders have been described $[10,13,18,19,112,117$, 118]. Following discontinuation of a long-term treatment with paroxetine, Shoenberger [117] first reported the emergence of persistent post-withdrawal panic disorder, which was some years later also documented by Bhanji et al. [18]. Fava et al. [19] conducted a study of gradual SSRI 
discontinuation in panic disorder and found that 3 out of the 9 patients treated with paroxetine had persistent postwithdrawal disorders after 1-year post-withdrawal. Belaise et al. [112] analyzed online reports from individuals who described persistent post-withdrawal disorders after SSRI discontinuation; the most frequent disorders were: disturbed mood, depression, emotional liability, mood swings, irritability, anxiety, insomnia, impaired concentration, impaired memory. In another study, following paroxetine cessation, Belaise et al. [118] reported the emergence of persistent post-withdrawal disorders such as pathological gambling and generalized anxiety. Stockmann et al. [119] analyzed the content of a sample of posts on an antidepressant withdrawal website and found that patients assessing antidepressant withdrawal websites report experienced persistent post-withdrawal disorders more frequently with SSRIs than SNRIs, with neurological symptoms more common among SNRI users and psychosexual/genitourinary symptoms more common among SSRI users. Finally, Chouinard and Chouinard [10] illustrated 3 cases of persistent post-withdrawal disorders: one had generalized anxiety disorder, one cyclothymic disorder, and one had major depressive episode with melancholic features. Overall, based on the literature here described, which is still limited, paroxetine seems at higher risk to induce persistent post-withdrawal disorders than other SSRIs.

Episodes of long duration of withdrawal symptoms (i.e., depression, anxiety, mania, tinnitus, nausea, unexplained fear, and dizziness) were described after SNRIs discontinuation, suggesting the occurrence of persistent post-withdrawal disorders [120-123]. To be noted that 3 out of the 4 studies reporting SNRI persistent post-withdrawal disorders were on venlafaxine [120-122] and 1 was on duloxetine [123].

Finally, since 2006, persistent sexual side effects after SSRIs and SNRIs discontinuation have been described [124]. These sexual manifestations have been rapidly identified as a syndrome called post-SSRI sexual dysfunction (PSSD) [125], that is a sexual dysfunction, caused by both SSRIs and SNRIs, characterized by a decrease or absence of libido, genital anesthesia, numbness in nipples, orgasmic disorders (i.e., anorgasmia or anhedonic orgasm), erectile dysfunction, delayed or premature ejaculation, testicular pain or atrophy (in males), lack of lubrication (in females) and by psychological symptoms such as anhedonia, difficulty in concentrating, memory problems, inability to experience sexual attraction to the sight, touch, or idea of a sexual partner [125-127]. The symptoms may last months or even years $[127,128]$. Recently,

Withdrawal Syndromes it has been described the case of a patient in which PSSD symptoms were part of a broader syndrome which was diagnosed as persistent post-withdrawal disorder [129]. This case rises the suspicion that PSSD might be a withdrawal syndrome occurring after decrease/discontinuation of SSRIs or SNRIs and that withdrawal symptoms might include a wider variety of sexual manifestations which are under-reported, probably due to a poor attention of clinicians toward sexual symptoms and a lack of investigations by clinicians as well as researchers [129].

\section{Associated Clinical Manifestations}

Withdrawal syndromes after decrease or discontinuation of antidepressants may be associated with additional clinical manifestations. They include modifications of the illness course, such as switching to mania or other forms of excessive behavioral activations [24], but also loss of clinical effects and refractoriness to treatment; they have been reported with SSRI and SNRI $[5,6,27]$. When mania or other forms of excessive behavioral activations occur, it may be self-limiting or may require specific anti-manic treatment [130]. Loss of clinical effects involves the return of symptoms during maintenance treatment that only temporarily respond to dose increase [25]. Refractoriness to treatment is the lack of response to a previously effective pharmacological treatment when it is started again after a drug-free period [25], as was reported in the case illustrated by Jha et al. [89].

\section{Management of SSRIs/SNRIs Discontinuation}

An initially hypothesized strategy to manage antidepressant withdrawal was restarting the antidepressant [97]; of course this meant for the patients never being able to decrease or discontinue the drug which was responsible for the withdrawal manifestation. Thereafter, it was proposed to switch to a longer half-life SSRI (i.e., fluoxetine) [111], since it is less likely to induce withdrawal problems; however, this switch may favor subsequent episodes of illness deterioration [27]. Another suggested option was slow tapering; however, it was shown that withdrawal symptoms and syndromes may occur during and despite slow tapering $[5,6]$. A hyperbolically decreasing pattern of SSRI dose decrease has been recently proposed to produce a linear reduction of pharmacological effect [131], but its validity needs to be tested in randomized controlled trials. A multistep dose reduction paradigm was suggested by Ruhe et al. [132]. In this paradigm, the initial step is to reduce the dose to half of the minimally effective dose in 1 week and then reduce very gradually. However, even this approach has not been tested yet. 
Regarding non-pharmacological interventions, when a group cognitive-behavioral therapy aimed at relapse prevention was proposed to patients who were tapering antidepressants within 4 months according to a fixed schedule, only $37 \%(n=26)$ of the subjects succeeded in discontinuing the drug and only $28 \%(n=20)$ succeeded in discontinuing without recurrence. This finding suggests that cognitive behavioral therapy does not help with antidepressants withdrawal. However, the results might be partly due to the timing of administration of the cognitive-behavioral therapy, which was simultaneous with the discontinuation period, although it is known that the right timing of cognitive-behavioral therapy is crucial [118], as well as to the vulnerability of the sample under study, the majority had unsuccessfully tried to discontinue before [133].

Fava and Belaise [27] proposed pharmacological (i.e., lessen withdrawal symptomatology by the use of psychotropic drugs that are not antidepressants, for instance clonazepam) and non-pharmacological (i.e., a 3-module intervention which includes explanatory therapy, cognitive behavioral treatment, and well-being therapy) strategies to manage SSRI withdrawal which are, however, based on their extensive clinical experience and in need of being tested in randomized clinical trials.

\section{Ketamine and Esketamine}

Esketamine, the enantiomer of ketamine and an NMDA receptor antagonist, has been marketed as nasal spray approved by the Food and Drug Administration (FDA) in 2019 for intranasal treatment of treatment-resistant depression in conjunction with an oral antidepressant $[134,135]$.

Ketamine (intravenous anesthetic) and esketamine (nasal spray) potentially produce psychological dependence and rapidly induce pharmacological tolerance [136-139]. Ketamine is used for recreational purposes because it produces mental and behavioral changes, such as euphoria, perceptual changes, dissociation, and hallucinations [140]. These effects, together with a risk of abuse and misuse, made ketamine a popular street drug, also known as "Special K" [141]. In addition, a prolonged exposure to ketamine may predispose to neurotoxicity [142].

Studies showing that esketamine has less risks of abuse than ketamine are lacking. Before approval, the FDA committee wrote in its documentation that "data on safety of ketamine may be considered relevant to discussions regarding the safety of esketamine [...]. The risks of abuse and associated harms are important considerations in determining appropriate risk mitigation strategies and post marketing surveillance for esketamine" [143]. Additionally, the FDA reported that the safety concerns for esketamine are misuse, abuse, dissociation, and sedation, for which a Risk Evaluation and Mitigation Strategy was planned [143, 144].

New acute withdrawal symptoms after ketamine discontinuation have been described. They are craving, dysphoria, shaking, sweating, palpitations, tiredness, low appetite, low mood, chills, autonomic arousal, lacrimation, restlessness, anxiety, nightmares, paranoia, delusions, and hallucinations [145-147]. Addiction websites (i.e., American Addiction Centers and Addiction Center) also mentioned agitation, confusion, loss of motor skills, rage, nausea, decreased respiratory and cardiac functions, insomnia, cognitive impairment, tremors [3]. New withdrawal symptoms typically begin within $24 \mathrm{~h}$ of discontinuation and last approximately 3 days, although in some cases, they may persist for 2 weeks and thereafter stabilize [3].

In view of the inevitable decay of the response to ketamine due to pharmacological tolerance [148] and its possible benefit as maintenance therapy in treatment-resistant depression [142], and considering that some clinicians use ketamine formulations for chronic use despite the alarm regarding "the rapid proliferation of off-label ketamine administration in the absence of evidence of lasting therapeutic benefit or safety with long-term administration" [p. 686 in 142], the use of ketamine in psychiatry is at risk of replicating the 2016 opioid US epidemic abuse [149] with the risk to induce neurotoxicity, which might be associated with persistent post-withdrawal disorders.

\section{Antipsychotics}

Chouinard et al. [9] described withdrawal reactions due to antipsychotics dose decrease, discontinuation, or switch and concluded that acute withdrawal symptoms, rebound, and persistent post-withdrawal disorders may occur and that 2 persistent post-withdrawal disorders, tardive dyskinesia and supersensitivity psychosis, were specifically induced by antipsychotics [21, 22, 150, 151]. Studies on withdrawal reactions associated with antipsychotics switch were extensively reviewed also by Cerovecki et al. [8] and similar conclusions were reached. 
In the era of first-generation antipsychotics (FGAs) both supersensitivity psychosis and tardive dyskinesia were widely studied [9]. Second-generation antipsychotics (SGAs) decreased the prevalence of drug-induced movement disorders, including tardive dyskinesia [13], but concerns [13] have remained about supersensitivity psychosis [9]. Since both FGAs and SGAs have shown to trigger withdrawal at decrease, switch, or discontinuation, we will here describe the literature on antipsychotics withdrawal using Chouinard and Chouinard [10] diagnostic criteria and highlighting the different impact, when present and available, of FGAs and SGAs.

\section{New Withdrawal Symptoms after Antipsychotic}

Discontinuation

New withdrawal symptoms following dose decrease, discontinuation, or switch may occur with any type of antipsychotic and include a wide range of symptoms [8, 9] which are reported in Table 4.

Chouinard et al. [9] described them as serotonin withdrawal syndrome (i.e., flu-like symptoms, sweating, chills; dizziness, light-headedness, tachycardia; diarrhea, loose stools, abdominal pain; restlessness, myalgia, rigidity, hyperreflexia, inducible clonus; paresthesia, electric shock sensations, zaps; confusion, disorientation, amnesia, coma; premature ejaculation, genital hypersensitivity), as muscarinic cholinergic withdrawal syndrome (i.e., agitation, insomnia, anxiety, depression; dizziness, light-headedness, tachycardia; nausea, vomiting, salivation, diarrhea, loose stools, abdominal cramp; tremor, parkinsonism, restlessness, myalgia, rigidity, myosis; paresthesia; confusion, disorientation; hypothermia, sweating, diaphoresis), as adrenergic withdrawal syndrome (i.e., headache, anxiety, agitation; increased blood pressure, increased heart rate, risk of myocardial infarction, angina pectoris, palpitations, chest pain; pre-syncope, tremulousness; sweating), and as histaminic withdrawal syndrome (i.e., irritability, depressed affect, insomnia, agitation; loss of appetite, nausea; tremulousness, incoordination, increased inducible seizure; lethargy, amnesia) [9].

Peaks of onset occur 36-96 h after decrease, discontinuation, or switch from and to SGAs, the symptoms are usually reversible and last from a few hours to 6 weeks [9].

Cerovecki et al. [8] summarized the studies reporting new withdrawal and rebound symptoms associated with switching from first- (mainly chlorpromazine, haloperidol, fluphenazine, amisulpride, sulpiride, zuclopenthixol) or SGAs (i.e., aripiprazole, clozapine, olanzapine, quetiapine, risperidone, ziprasidone) to SGAs (i.e., aripiprazole, asenapine, olanzapine, paliperidone, quetiapine, risperidone, ziprasidone). They evaluated 61 studies and 7 case reports. Among the 61 studies, 32 (52\%) did not report withdrawal or rebound symptoms, while 14 reported new withdrawal symptoms. Among the case reports, 5 did not report new withdrawal or rebound symptoms. In 1 case, the switching from clozapine triggered new withdrawal symptoms.

Overall, SGAs are associated as frequently with new withdrawal symptoms as FGAs, when we take into consideration the early 1960-1970 studies of FGAs.

\section{Rebound Symptoms after Antipsychotic \\ Discontinuation}

Rebound symptoms have been described during discontinuation and switch [9]. Rebound psychosis is a rapid return above pretreatment levels of original symptoms (i.e., illusion, hallucination, catatonia, passivity experience, delusion) [152, 153]. It is generally short lasting (i.e., $<6$ weeks after peak onset) [13] and is considered a reversible form of supersensitivity psychosis, equivalent to reversible withdrawal tardive dyskinesia [13].

In their review, Cerovecki et al. [8] reported even rebound symptoms associated with switching from first- or SGAs to SGAs. Among the 61 studies evaluated, 22 (36\%) reported rebound symptoms. Among the 7 case reports, no case reports documented rebound symptoms. Rebound psychosis appears as frequently with SGAs than with FGAs.

Among, SGAs, the phenomenon was first recognized to occur with clozapine $[9,13,154-156]$ and quetiapine monotherapy [157], later with other SGAs [158-160], overt frequency depending of their elimination half-life and potency. Antipsychotics rapidly eliminated or rapidly dissociated from the D2 receptors (i.e., clozapine, quetiapine) $[161,162]$ are known to have greater risks of rebound when medication is decreased, switched, or discontinued [13, 154, 156, 157, 163].

Patients on clozapine monotherapy taken as a single dose at bedtime report late afternoon return of symptoms [13]. For quetiapine, it is common clinical practice to have difficulty to decrease the drug, having first rebound anxiety and rebound insomnia, and later an in-between dose clock watching for return of symptoms (i.e., patient watches the clock to make sure the next dose is not missed for fear that symptoms might return) $[9,10,13,163]$.

\section{Persistent Post-Withdrawal Disorders after \\ Antipsychotic Discontinuation}

Persistent post-withdrawal disorders, that is a condition in which rebound symptoms and/or new withdraw- 
al symptoms and/or emerging new psychotic symptoms of another type, such as disorganized behavior, persist longer than 6 weeks, have been described after discontinuation of antipsychotics. In addition to the several clinical manifestations of persistent post-withdrawal disorders which have been observed also for other psychotropic medication classes, 2 specific persistent post-withdrawal disorders, named persistent post-withdrawal tardive dyskinesia and persistent post-withdrawal supersensitivity psychosis, have been well described [21, $22,150,151]$. Thus, when dyskinesia or psychosis last $<6$ weeks after discontinuation, they are considered new withdrawal dyskinesia/psychosis or rebound psychosis, and when they last longer than 6 weeks, they become persistent post-withdrawal disorders $[9,13]$.

Persistent post-withdrawal tardive diskinesia is characterized by a hyperkinetic, involuntary, and purposeless movement disorder [10] occurring after decrease, discontinuation, or switch of antipsychotics. It has been documented to occur after short-term use (1-month) of chlorpromazine in a patient with schizophrenia [164], and in a non-psychiatric patient after a 4-month treatment with a gastric preparation containing trifluoperazine and an anticholinergic drug. In the latter case, 7 weeks after the termination of the treatment, continuous movements of the patient's face, lips, and tongue appeared; they were irreversible and extremely severe [165].

Persistent post-withdrawal supersensitivity psychosis is characterized by rebound and/or new withdrawal psychosis occurring after decrease, discontinuation, or switch of antipsychotics which is associated with rapid appearance or reappearance of positive symptoms (i.e., illusion, hallucination, catatonia, Schneider passivity experience, delusion) and with the emergence of one definite drug-induced movement disorder, including tardive dyskinesia or prior movement disorder. Drug tolerance is present since positive symptoms cannot be controlled by an increase or by the re-introduction of the antipsychotic. The peak onset is within $24 \mathrm{~h}$ to 6 weeks after decrease, discontinuation, or switch for oral medications; for longacting injectable antipsychotics, the peak onset occurs 1-7 days before receiving the next injection or end of injection dosing interval determined by terminal plasma half-life [166]. Positive symptoms last $>6$ weeks after peak onset [22]. Kimura et al. [158] studied long-acting injectable risperidone as adjunctive therapy to treatment-resistant schizophrenia in a 1-year multicenter prospective follow-up study, the mean dose was equivalent to 1,000 $\mathrm{mg} /$ day chlorpromazine. They found a prevalence of SP of $65 \%$. At baseline, schizophrenia patients with SP had higher total scores for drug-induced movement disorders on the Extrapyramidal Symptom Rating Scale and higher scores on the negative symptoms sub-scale of the Brief Psychiatric Rating Scale. The SP group showed significantly greater improvement on the Brief Psychiatric Rating Scale total score than non-SP group. Kimura et al. [167] did a second-year follow-up, similar results were found. Patients with SP showed greater improvement on positive and negative symptoms and significantly less relapses during the first- and second-year follow-up, compared to treatment-resistant patients without SP. Takase et al. [159] retrospectively examined the clinical characteristics of schizophrenic patients with supersensitivity psychosis who had their antipsychotic treatment gradually switched to aripiprazole. They found a prevalence rate of supersensitivity psychosis of $26.5 \%$, that significantly more patients with supersensitivity psychosis had worsening of their positive symptoms compared to nonsupersensitivity psychosis patients, and that significantly less patients with supersensitivity psychosis were able to continue aripiprazole compared to non-supersensitivity psychosis patients. Suzuki et al. [160] examined supersensitivity psychosis in treatment-resistant schizophrenic patients and found a prevalence of $72 \%$ for at least one supersensitivity psychosis episode among those treated with SGAs (i.e., olanzapine, paliperidone, perospirone, quetiapine, and risperidone).

The Kimura et al. [167] and the Suzuki et al. [160] studies highlight the clinical characteristics of supersensitivity psychosis patients in the era of SGAs: high prevalence of drug-resistance, increased risk for drug-induced movement disorders, use of high chlorpromazine-equivalent doses, and a better clinical response in patients with supersensitivity psychosis compared to patients without supersensitivity psychosis.

Drugs such as fluphenazine, perphenazine, quetiapine, and clozapine permitted the identification of persistent post-withdrawal disorders [10, 13, 18, 19, 156, 157]. The manifestation and persistence of the supersensitivity psychosis depend on the specific antipsychotics used (i.e., fluphenazine, perphenazine, clozapine, quetiapine) [10, 13], the duration of D2-receptor blockade [168], and the continuous use.

\section{Associated Clinical Manifestations}

Persistent post-withdrawal tardive diskinesia and persistent post-withdrawal supersensitivity psychosis may be associated with additional clinical manifestations. They include loss of clinical effects, modifications of the illness course, and refractoriness to treatment $[169,170]$. 
Loss of clinical effects implies the occurrence of relapse in treatment adherent schizophrenic patients who did not discontinue or decrease or switch the drug $[169,170]$. Relapse is also characterized by modifications of the illness course: positive psychotic symptoms are more severe [169], the duration of the episode is longer [169], and more residual negative symptoms occur [170]. Refractoriness to treatment is another possible manifestation since relapse occurs when the patients are treated with higher doses of antipsychotics [169].

\section{Management of Antipsychotic Discontinuation}

A gradual decrease over a long period of time, over several months when clinically appropriate, was suggested to reduce the severity of new withdrawal and rebound symptoms [1], however this strategy does not reduce the risk of occurrence of new withdrawal and rebound symptoms and has not shown effects on persistent post-withdrawal disorders [9]. The use of adjunctive long half-life drugs, such as long-acting injectable SGAs, and antiseizure drugs has been proposed for the treatment of withdrawal syndromes [9]. Lamotrigine and antiseizure drugs (in particular valproic acid, carbamazepine, phenytoin) have been suggested as useful for supersensitivity psychosis [171], while clozapine and risperidone were considered palliative treatment [158-160]. Limited data are presently available for other potential pharmacological intervention of supersensitivity psychosis (e.g., clozapine, asenapine, blonanserin) [9].

Given the evidence for the risk of rebound withdrawal with quetiapine, doses $\leq 150 \mathrm{mg} /$ day of quetiapine as adjunctive therapy instead of monotherapy was recommended $[157,172]$. When giving quetiapine as adjunctive or monotherapy for 2 months and more, attempts to decrease the dose with alternate dosing interval or with gradual decrease of quetiapine daily dose were recommended [9].

\section{Lithium}

The evidence for withdrawal after lithium decrease or discontinuation is weak and ambiguous. Early manic and depressive recurrences after lithium discontinuation may suggest rebound symptoms, but studies carried out with appropriate methodology failed to confirm it [173]. Anxiety, sleep problems, and irritability following lithium discontinuation were suggested as new withdrawal symptoms in one review [174] and in one study [175]. No data on persistent post-withdrawal disorders are available.

Withdrawal Syndromes

\section{Other Mood Stabilizers}

Food and Drug Administration approved anticonvulsants for the treatment of bipolar disorder in adults; they are carbamazepine, valproate, lamotrigine [176].

The literature on withdrawal after decrease or discontinuation of carbamazepine in psychiatric patients is limited. However, a preliminary study on carbamazepineassociated withdrawal reaction after microvascular decompression to treat trigeminal neuralgia showed the occurrence of new withdrawal symptoms (i.e., insomnia, dysphoria, hand fremitus, hallucination, severe headache), which were found dependent on the pre-operative dosage of carbamazepine and the changing rate of preand post-operative drug blood concentrations [177]. In addition, in patients with active epilepsy, the following new withdrawal symptoms were observed at decrease of carbamazepine (which was part of a programmed rationalization of therapy for each patient): anxiety, tension, agitation, irritability, lack of energy, impaired memory/ concentration, depression, depersonalization, insomnia, anorexia, headache, muscle aches, twitching, tremor, shaking, dizziness, incoordination, paranoia, hyper-reflexia, gait ataxia, hypotension, tachycardia, faintness [178].

Also, the literature on withdrawal due to decrease or discontinuation of valproate or lamotrigine in psychiatric patients seems limited although some studies on epileptic patients are available. Duncan et al. [178] found the following new withdrawal symptoms at decrease of sodium valproate in patients with active epilepsy: anxiety, agitation, irritability, lack of energy, impaired memory/concentration, depression, depersonalization, insomnia, anorexia, tension, headache, muscle ache, twitching, nausea/vomiting, tremor, shaking, hyperreflexia, sweating, dizziness, photophobia, incoordination, faintness, tachycardia. However, in Duncan et al. [178] study, which was also mentioned for carbamazepine, new withdrawal symptoms occurred also in those who remained on stable therapy (the entire study was double-blind, with matching placebos replacing active drug in a stepwise fashion). Gelisse et al. [179] observed a case who presented anhedonia, tremor, slight tachycardia, and severe hands hyperhidrosis, which were considered new withdrawal reactions to lamotrigine discontinuation. In addition, 6 epileptic patients on stable-dose lamotrigine monotherapy presented end-of-dose new withdrawal symptoms (i.e., anxiety, emotional lability, irritability) [180].

No data are available on rebound symptoms and persistent post-withdrawal disorders.

Psychother Psychosom 2020;89:283-306

DOI: $10.1159 / 000506868$ 
Table 5. Withdrawal at decrease, discontinuation, or switch of psychotropic medications

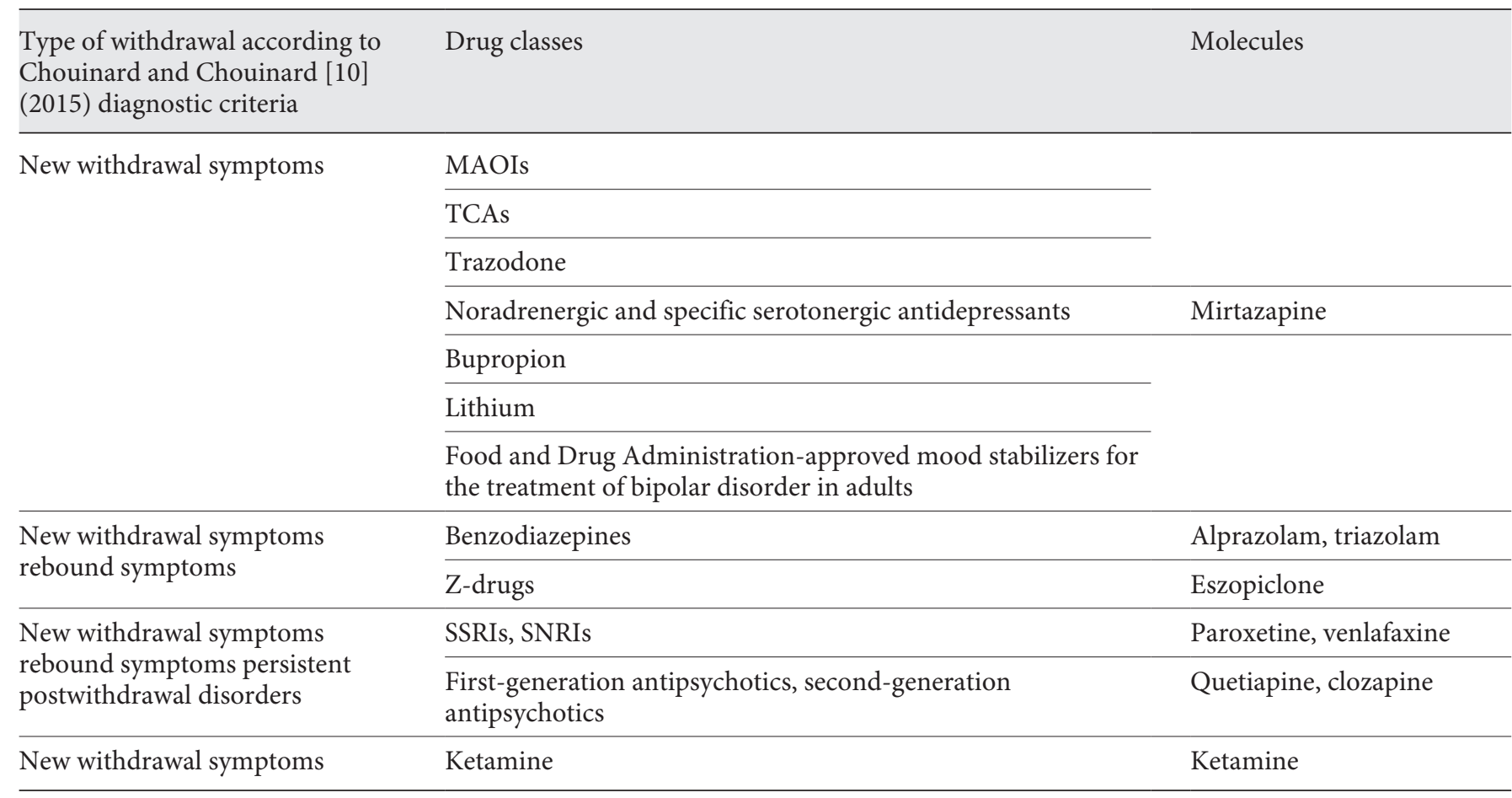

TCAs, tricyclic antidepressants; SSRIs, selective serotonin reuptake inhibitors; SNRIs, serotonin noradrenaline reuptake inhibitors; MAOIs, monoamine oxidase inhibitors.

Considering that the phenomenon of withdrawal after discontinuation of anticonvulsants seems documented in the neurologic literature only, attention on this topic should be turned on by psychiatrists who use anticonvulsants as mood stabilizers.

\section{Discussion}

Psychotropic Medications in the Debate on Substance Use Disorders

Like all other pharmacological agents used in medicine, psychotropic medications discontinuation can induce withdrawal syndromes but not all psychotropic medications are the same between classes and within a class $[13,181]$. A summary of the types of withdrawal at decrease, discontinuation, or switch of psychotropic medications is proposed in Table 5. Ketamine has a capacity to induce drug use disorders including psychological problems and tolerance. In addition, SSRIs, SNRIs, antipsychotics were consistently associated with persistent post-withdrawal disorders and increased severity of illness symptoms, including alterations of clinical course. Regarding specific molecules, alprazolam, lorazepam, triazolam, paroxetine, venlafaxine, clozapine, and quetiapine are more likely to induce withdrawal than other compounds of the same class.

Table 5 content should be evaluated under the light of the timing of release on the market of the different classes of drugs. Additional research reports may come for Zdrugs, the more recent zaleplon was approved only in 1999. The literature on SNRIs may increase since they were released 13 years later SSRIs. Additional evidence is also expected for new antidepressants. Interestingly, although esketamine was approved only on March 05, 2019 by the FDA as medication for treatment-resistant depression, the literature on ketamine already shows new withdrawal symptoms and neurotoxicity, which may indicate future evidence of persistent post-withdrawal disorders. Finally, knowledge on FDA-approved mood stabilizers for the treatment of bipolar disorder in adults is limited to the neurologic field.

In this framework, it seems important to clarify whether the clinical phenomenon of withdrawal can equate psy- 
chotropic medications (especially SSRIs, SNRIs, and antipsychotics) to substances.

It has been suggested that the presence of withdrawal symptoms is not enough to establish a diagnosis of substance-induced disorder. Moreover, the DSM-5 [182] suggested that the criterion of withdrawal is not considered to be met for individuals taking psychotropic medications under medical supervision [183]. One direct implication is that clinicians have been forced to use antidepressants, or even antipsychotics, in anxiety disorders because benzodiazepines were claimed to be addictive; and mental health professionals receive poor academic teaching and training regarding these agents [184]. For instance, Batelaan et al. [185] recommendation for chronic antidepressant treatment of anxiety disorders, instead of benzodiazepines, seems to be misleading based on the results of the present overview of the literature and on the observation that benzodiazepines are at least as effective as antidepressants for treatment of anxiety disorders [186]. The International Task Force on Benzodiazepines suggested that benzodiazepines have not been adequately compared to other psychotropic medications in various indications, and their risks and side effects have been overemphasized [187].

The debate on abuse, dependence, and addiction of psychotropic medications seems endless and apparently unresolved. What is needed is a better understanding of withdrawal syndromes and pharmacological dependence, which is already evident for instance for ketamine, and engage in evidence-based, open-minded discussions about these important classes of medication.

\section{Psychotropic Medications in the Debate on Tolerance}

In 1968-1969, DiMascio et al. [188-190] described the pharmacological actions of a drug that, within the dose range in which it has clinical utility, may produce alterations in mood, perceptual, cognitive, and psychomotor functions that limit the capacity of the individual or constitute a hazard to his well-being. Examples of such tolerance phenomena are switching from unipolar to bipolar course $[24,45]$ and increased chronicity of affective disorders [191] with antidepressants, supersensitivity psychosis with antipsychotic medications [9]. Paradoxical reactions may occur, such as increased agitation, excitement, insomnia, and talkativeness with benzodiazepines [192]; restlessness and agitation with antidepressants. Tolerance may also entail subtle manifestations such as cognitive impairment associated with psychotropic drugs $[193,194]$, apathy related to the use of antidepressants [195], and depression [196] related to the use of antipsy- chotics. Withdrawal symptoms which may follow discontinuation of psychotropic drugs, and in particular persistent post-withdrawal disorders, as well as their associated clinical manifestations, such as modifications of the illness course and refractoriness to treatment, are also a tolerance manifestation [24].

Tolerance thus manifests as adverse drug reactions (ADR), which are undesired effects of a medication that increases toxicity or decreases desired therapeutic effect or both [197] and which can occur right after the therapy or even during therapy [198]. When ADR related to tolerance are misinterpreted or simply ignored, a cascade iatrogenesis - a serial development of multiple medical complications that can be set in motion by a seemingly innocuous first event $[28,199]$ - may result together with iatrogenic comorbidity, that is, the unfavorable modifications in the course, characteristics, and responsiveness to a treatment of an illness related to treatments previously administered [5, 24, 200-202].

The oppositional model of tolerance offers a unitary view for the clinical phenomena described [201, 203]. According to this, continued drug treatment may recruit processes that oppose the initial acute effects of a drug; this may explain loss of treatment efficacy and the fact that certain side effects (such as increased appetite and weight gain) tend to ensue only after a certain time. These processes may also propel the illness to a more malignant and treatment-unresponsive course, as with bipolar depression [24, 45], apathy [195], or paradoxical reactions. When drug treatment ends, oppositional processes may encounter no more resistance, resulting in the appearance of withdrawal manifestations, hypomania, and resistance to treatment if it is reinstituted. In the long run, antidepressants may increase chronicity, vulnerability to depressive disorders, and comorbidity [26, 204]. The model is complex and multifactorial and is influenced by the duration of and prior exposure to drug treatment as well as by psychosocial and genetic factors [201].

\section{Clinical Implications}

A solid clinical competence in recognizing withdrawal phenomena, and later formulating the correct diagnosis, is needed. Apparently recognizing withdrawal syndromes is highly challenging for clinicians, since they may not fit with the diagnostic criteria described by the DSM-5 [182] and the ICD-11 [205] and they may include physical manifestations which do not subsume under the rubric of codified organic illnesses. Current diagnostic methods in psychiatry, both DSM-5 [182] and ICD-11 [205], are inadequate to assess psychotropic medication withdrawal 
because they do not take into account the issue of iatrogenic comorbidity [28] and they refer to drug-free patients, although most of the psychiatric cases seen at first visit in psychiatry and in clinical psychology are already under a psychotropic medication [28]. As a result, patients experiencing anguish and mental pain [206-208] of withdrawal syndromes have not received appropriate medical attention [27].

In addition to the limitations of the current nosography, the standard clinical interview nowadays include data on type, dose, duration, and efficacy of treatments received while a crucial point in collecting data about previous treatments would be investigating the occurrence of ADR related to tolerance [28]. Once such data have been obtained, the clinician is asked to place them within the context of psychiatric and medical morbidity. Thus, when the psychiatrist approaches patients' complaints, he should consider different and interconnected pathways which include biological, psychological, and social factors of iatrogenic nature whose consequences may be considered potentially counter-therapeutic [209].

\section{Research Implications}

New withdrawal symptoms, rebound symptoms, and persistent post-withdrawal disorders which occur after decrease, switch, or discontinuation of psychotropic medications are very likely to affect the findings of randomized controlled trials [210,211].

Randomized controlled trials tend to deliberately incorporate in their design a drug discontinuation procedure in order to reach conclusions about drugs' effectiveness in preventing relapse or recurrence of mental disorder [210]. In particular, in relapse prevention randomized controlled trials, researchers place participants on a drug, divide them into responders and nonresponders, and responders are randomized to remain on the drug or discontinue it. If at the end of this randomized discontinuation phase, outcome measures favor the drug-maintained group, investigators conclude that the drug is effective [211]. It follows that withdrawal after discontinuation of the previous treatment may confound trial outcomes [211] both increasing the impact of randomization to the new drug and misleadingly increasing ratings of adverse effects [212]. Such designs also risk exaggerating contrasts in morbidity between subjects continuing a treatment proven as effective versus being withdrawn to another treatment or an inactive placebo $[211,213]$. As a consequence, the results of such trials may be confounded by the failure to account for drug withdrawal symptoms [211], they are likely to provide inadequate and confounded evidence of potential long-term or prophylactic benefits $[214,215]$, and their scientific soundness seems compromised [212].

Withdrawal must be considered and assessed when clinical trials are run; this will allow the possibility to reproduce, in research, conditions which are a true proxy of those occurring in the clinic realm.

\section{Conclusions}

Withdrawal after psychotropic medication discontinuation represents a major challenge in research and clinical practice, there are still major difficulties in distinguishing symptoms of the disease and those induced by the treatment and the information available from randomized controlled trials is questionable, scanty, and inadequate $[216,217]$. There is also reluctance toward accepting that psychoactive drugs can cause withdrawal, which is paradoxical and potentially dangerous. The paradox is related to the fact that DSM-5 describes withdrawal (p. 484) [182] and the essential feature for substance withdrawal (p. 486) [182], but although these criteria nicely fit into the new withdrawal symptoms described for psychotropic medications, they are not commonly used for this purpose. There is danger in that patients presenting withdrawal syndromes are at risk of being misdiagnosed, mistreated, and entering the cascade iatrogenesis, which is the front door for chronicity. This is true also in clinical practice in children and adolescents in which withdrawal syndromes can occur, much more caution is needed, and there is almost no literature [202].

Clinicians and researchers should accept that subjects in trials and real-life patients are no more drug-naïve, or even drug-free, the rule is being under polypharmacy $[218,219]$. Unfortunately, this is simply not addressed by the literature although commonly encountered in clinical reality. There are important issues that need to be explored, and we have tools such as the DiscontinuationEmergent Signs and Symptoms [111] and the Diagnostic clinical Interview for Drug Withdrawal 1 - New Symptoms of SSRI and SNRI [220] which can help. The most urgent are neurobiological studies to shed some light on why certain patients develop withdrawal syndromes and others do not; longitudinal studies exploring the occurrence, clinical features, and neurobiological correlates of persistent post-withdrawal disorders are warranted as well as well-designed randomized controlled trials with 
appropriately titrated doses of medication comparing different strategies of psychotropic medication discontinuation, comparing different methods of managing withdrawal syndromes (including adjunctive psychotherapeutic strategies), and considering the possibility that withdrawal syndromes may be confounded with relapses in long-term drug/placebo continuations studies [201]. Clinical pharmachopsychology [221, 222], the discipline applying clinimetric methods to the assessment of psychotropic effects of medications, may provide additional sources of information.

\section{Disclosure Statement}

The copyright of the DID-W1, The Diagnostic clinical Interview for Drug Withdrawal 1 - New Symptoms of SSRI and SNRI, was deposited by the University of Florence, Florence, Italy, at the request of F.C. and based on a copyright management agreement with G.C.

\section{Author Contributions}

Both authors run the literature search. F.C. wrote the drafts of the papers. G.C. revised all the drafts and added materials, texts, references.

\section{References}

1 Fontaine R, Chouinard G, Annable L. Rebound anxiety in anxious patients after abrupt withdrawal of benzodiazepine treatment. Am J Psychiatry. 1984 Jul;141(7):848-52.

2 Ostrow L, Jessell L, Hurd M, Darrow SM, Cohen D. Discontinuing Psychiatric Medications: A Survey of Long-Term Users. Psychiatr Serv. 2017 Dec;68(12):1232-8.

3 Lerner A, Klein M. Dependence, withdrawal and rebound of CNS drugs: an update and regulatory considerations for new drugs development. Brain Communications. 2019 Oct;1(1):fcz025.

4 Nielsen M, Hansen EH, Gøtzsche PC. What is the difference between dependence and withdrawal reactions? A comparison of benzodiazepines and selective serotonin re-uptake inhibitors. Addiction. 2012 May;107(5):900-8.

5 Fava GA, Gatti A, Belaise C, Guidi J, Offidani E. Withdrawal Symptoms after Selective Serotonin Reuptake Inhibitor Discontinuation: A Systematic Review. Psychother Psychosom. 2015;84(2):72-81.

6 Fava GA, Benasi G, Lucente M, Offidani E, Cosci F, Guidi J. Withdrawal Symptoms after Serotonin-Noradrenaline Reuptake Inhibitor Discontinuation: systematic Review. Psychother Psychosom. 2018;87(4):195-203.

7 Davies J, Read J. A systematic review into the incidence, severity and duration of antidepressant withdrawal effects: are guidelines evidence-based? Addict Behav. 2019 Oct;97: $111-21$.

8 Cerovecki A, Musil R, Klimke A, Seemüller F, Haen E, Schennach R, et al. Withdrawal symptoms and rebound syndromes associated with switching and discontinuing atypical antipsychotics: theoretical background and practical recommendations. CNS Drugs. 2013 Jul;27(7):545-72.

9 Chouinard G, Samaha AN, Chouinard VA, Peretti CS, Kanahara N, Takase M, et al. Antipsychotic-Induced Dopamine Supersensitivity Psychosis: Pharmacology, Criteria, and Therapy. Psychother Psychosom. 2017;86(4): 189-219.
10 Chouinard G, Chouinard VA. New Classification of Selective Serotonin Reuptake Inhibitor Withdrawal. Psychother Psychosom. 2015;84(2):63-71.

11 Covi L, Lipman RS, Pattison JH, Derogatis LR, Uhlenhuth EH. Length of treatment with anxiolytic sedatives and response to their sudden withdrawal. Acta Psychiatr Scand. 1973; 49(1):51-64.

12 Chouinard G, Bradwejn J, Annable L, Jones $\mathrm{BD}$, Ross-Chouinard A. Withdrawal symptoms after long-term treatment with low-potency neuroleptics. J Clin Psychiatry. 1984 Dec;45(12):500-2.

13 Chouinard G, Chouinard VA. Atypical antipsychotics: CATIE study, drug-induced movement disorder and resulting iatrogenic psychiatric-like symptoms, supersensitivity rebound psychosis and withdrawal discontinuation syndromes. Psychother Psychosom. 2008;77(2):69-77.

14 Chouinard G. Issues in the clinical use of benzodiazepines: potency, withdrawal, and rebound. J Clin Psychiatry. 2004;65(Suppl 5): $7-12$.

15 Busto U, Sellers EM, Naranjo CA, Cappell H, Sanchez-Craig M, Sykora K. Withdrawal reaction after long-term therapeutic use of benzodiazepines. N Engl J Med. 1986 Oct; 315(14):854-9.

16 Black K, Shea C, Dursun S, Kutcher S. Selective serotonin reuptake inhibitor discontinuation syndrome: proposed diagnostic criteria. J Psychiatry Neurosci. 2000 May;25(3):25561.

17 Kales A, Scharf MB, Kales JD. Rebound insomnia: a new clinical syndrome. Science. 1978 Sep;201(4360):1039-41.

18 Bhanji NH, Chouinard G, Kolivakis T, Margolese HC. Persistent tardive rebound panic disorder, rebound anxiety and insomnia following paroxetine withdrawal: a review of rebound-withdrawal phenomena. Can J Clin Pharmacol. 2006;13(1):e69-74.
19 Fava GA, Bernardi M, Tomba E, Rafanelli C. Effects of gradual discontinuation of selective serotonin reuptake inhibitors in panic disorder with agoraphobia. Int J Neuropsychopharmacol. 2007 Dec;10(6):835-8.

20 Chouinard G. Rebound Anxiety: Incidence and relationship to subjective cognitive impairment. J Clin Psychiatry. 1986;4(1):12-16.

21 Chouinard G, Jones BD. Neuroleptic-induced supersensitivity psychosis: clinical and pharmacologic characteristics. Am J Psychiatry. 1980 Jan;137(1):16-21.

22 Chouinard G, Jones BD, Annable L. Neuroleptic-induced supersensitivity psychosis. Am J Psychiatry. 1978 Nov;135(11):1409-10.

23 Kosten TR, O'Connor PG. Management of drug and alcohol withdrawal. N Engl J Med. 2003 May;348(18):1786-95.

24 Fava GA, Cosci F, Offidani E, Guidi J. Behavioral Toxicity Revisited: Iatrogenic Comorbidity in Psychiatric Evaluation and Treatment. J Clin Psychopharmacol. 2016 Dec; 36(6):550-3.

25 Fava GA. Rational use of antidepressant drugs. Psychother Psychosom. 2014;83(4): 197-204.

26 Bosman RC, Waumans RC, Jacobs GE, Voshaar O, Muntingh AD, Batelaan NM, et al. Failure to Respond after Reinstatement of Antidepressant Medication: A Systematic Review. Psychother Psychosom. 2018;87(5): 268-75.

27 Fava GA, Belaise C. Discontinuing Antidepressant Drugs: Lesson from a Failed Trial and Extensive Clinical Experience. Psychother Psychosom. 2018;87(5):257-67.

28 Fava GA, Rafanelli C. Iatrogenic Factors in Psychopathology. Psychother Psychosom. 2019;88(3):129-40.

29 Committee on the Review of Medicines. Systematic review of the benzodiazepines. Guidelines for data sheets on diazepam, chlordiazepoxide, medazepam, clorazepate, lorazepam, oxazepam, temazepam, triazolam, nitrazepam, and flurazepam. BMJ. 1980 Mar;280(6218):910-2. 
30 Marks J. The benzodiazepines: use, overuse, misuse, abuse. Lancaster: MTP; 1978.

31 Hair PI, McCormack PL, Curran MP. Eszopiclone: a review of its use in the treatment of insomnia. Drugs. 2008;68(10):1415-34.

32 Morgenthaler TI, Silber MH. Amnestic sleeprelated eating disorder associated with zolpidem. Sleep Med. 2002 Jul;3(4):323-7.

33 MacFarlane J, Morin CM, Montplaisir J. Hypnotics in insomnia: the experience of zolpidem. Clin Ther. 2014 Nov;36(11):1676-701.

34 Finsterer J, Frank M. Zolpidem-triggered seizures, depression, and reduced locomotion. J Clin Neurosci. 2016 Nov;33:271-2.

35 Haji Seyed Javadi SA, Hajiali F, Nassiri-Asl M. Zolpidem dependency and withdrawal seizure: a case report study. Iran Red Crescent Med J. 2014 Nov;16(11):e19926.

36 Fontaine R, Beaudry P, Le Morvan P, Beauclair L, Chouinard G. Zopiclone and triazolam in insomnia associated with generalized anxiety disorder: a placebo-controlled evaluation of efficacy and daytime anxiety. Int Clin Psychopharmacol. 1990 Jul;5(3):173-83.

37 Lader M, Kyriacou A. Withdrawaing benzodiazepines in patients with anxiety disorders. Curr Psychiatry Rep. 2016 Jan;18(1):8.

38 Tyrer P, Rutherford D, Huggett T. Benzodiazepine withdrawal symptoms and propranolol. Lancet. 1981 Mar;1(8219):520-2.

39 Petursson H, Lader MH. Withdrawal from long-term benzodiazepine treatment. Br Med J (Clin Res Ed). 1981 Sep;283(6292):643-5.

40 Petursson H, Lader MH. Benzodiazepine dependence. Br J Addict. 1981;76(2):133-45.

41 Ashton H. Protracted withdrawal syndromes from benzodiazepines. J Subst Abuse Treat. 1991;8(1-2):19-28.

$42 \mathrm{Hu} \mathrm{X}$. Benzodiazepine withdrawal seizures and management. J Okla State Med Assoc. $2011 \mathrm{Feb} ; 104(2): 62-5$.

43 Marriott S, Tyrer P. Benzodiazepine dependence. Avoidance and withdrawal. Drug Saf. 1993 Aug;9(2):93-103.

44 Teboul E, Chouinard G. A guide to benzodiazepine selection. Part II: clinical aspects. Can J Psychiatry. 1991 Feb;36(1):62-73.

45 Carvalho AF, Sharma MS, Brunoni AR, Vieta E, Fava GA. The safety, tolerability and risks associated with the Use of Newer Generation Antidepressant Drugs: a critical review of the literature. Psychother Psychosom. 2016; 85(5):270-88.

46 Noyes R Jr, Garvey MJ, Cook BL, Perry PJ. Benzodiazepine withdrawal: a review of the evidence. J Clin Psychiatry. 1988 Oct;49(10): 382-9.

47 Smith DE, Wesson DR. Benzodiazepine dependency syndromes. J Psychoactive Drugs. 1983 Jan-Jun;15(1-2):85-95.

48 Teboul E, Chouinard G. A guide to benzodiazepine selection. Part I: pharmacological aspects. Can J Psychiatry. 1990 Nov;35(8):70010.

49 Pétursson $\mathrm{H}$. The benzodiazepine withdrawal syndrome. Addiction. 1994 Nov;89(11): 1455-9.
50 Rickels K, Fox IL, Greenblatt DJ, Sandler KR, Schless A. Clorazepate and lorazepam: clinical improvement and rebound anxiety. Am J Psychiatry. 1988 Mar; 145(3):312-7.

51 Rickels K, Case WG, Schweizer EE, Swenson C, Fridman RB. Low-dose dependence in chronic benzodiazepine users: a preliminary report on 119 patients. Psychopharmacol Bull. 1986;22(2):407-15.

52 Cloos JM, Bocquet V, Rolland-Portal I, Koch $\mathrm{P}$, Chouinard G. Hypnotics and Triazolobenzodiazepines-Best Predictors of High-Dose Benzodiazepine Use: Results from the Luxembourg National Health Insurance Registry. Psychother Psychosom. 2015;84(5):273-83.

53 Kales A, Kales JD, Bixler EO, Scharf MB, Russek E. Hypnotic efficacy of triazolam: sleep laboratory evaluation of intermediateterm effectiveness. J Clin Pharmacol. 1976 Aug-Sep;16(8-9):399-406.

54 Vogel GW, Barker K, Gibbons P, Thurmond A. A comparison of the effects of flurazepam $30 \mathrm{mg}$ and triazolam $0.5 \mathrm{mg}$ on the sleep of insomniacs. Psychopharmacology (Berl). 1976 May;47(1):81-6.

55 Bliwise D, Seidel W, Greenblatt DJ, Dement W. Nighttime and daytime efficacy of flurazepam and oxazepam in chronic insomnia. Am J Psychiatry. 1984 Feb;141(2):191-5.

56 Mitler MM, Seidel WF, van den Hoed J, Greenblatt DJ, Dement WC. Comparative hypnotic effects of flurazepam, triazolam, and placebo: a long-term simultaneous nighttime and daytime study. J Clin Psychopharmacol. 1984 Feb;4(1):2-13.

57 Kales A, Bixler EO, Vela-Bueno A, Soldatos CR, Niklaus DE, Manfredi RL. Comparison of short and long half-life benzodiazepine hypnotics: triazolam and quazepam. Clin Pharmacol Ther. 1986 Oct;40(4):378-86.

58 Hajak G, Clarenbach P, Fischer W, Rodenbeck A, Bandelow B, Broocks A, et al. Rebound insomnia after hypnotic withdrawal in insomniac outpatients. Eur Arch Psychiatry Clin Neurosci. 1998;248(3):148-56.

59 Soldatos CR, Dikeos DG, Whitehead A. Tolerance and rebound insomnia with rapidly eliminated hypnotics: a meta-analysis of sleep laboratory studies. Int Clin Psychopharmacol. 1999 Sep;14(5):287-303.

60 Adam K, Adamson L, Brezinová V, Hunter WM. Nitrazepam: lastingly effective but trouble on withdrawal. BMJ. 1976 Jun;1(6025): 1558-60.

61 Kales A, Bixler EO, Soldatos CR, Vela-Bueno A, Jacoby J, Kales JD. Quazepam and flurazepam: long-term use and extended withdrawal. Clin Pharmacol Ther. 1982 Dec;32(6):781-8.

62 Kales A, Bixler EO, Soldatos CR, Jacoby JA, Kales JD. Lorazepam: effects on sleep and withdrawal phenomena. Pharmacology. 1986;32(3):121-30

63 Kales A, Manfredi RL, Vgontzas AN, Bixler EO, Vela-Bueno A, Fee EC. Rebound insomnia after only brief and intermittent use of rapidly eliminated benzodiazepines. Clin Pharmacol Ther. 1991 Apr;49(4):468-76.
64 Bixler EO, Kales A, Soldatos CR, Scharf MB, Kales JD. Effectiveness of temazepam with short-intermediate-, and long-term use: sleep laboratory evaluation. J Clin Pharmacol. 1978 Feb-Mar;18(2-3):110-8.

65 Mitler MM, Carskadon MA, Phillips RL, Sterling WR, Zarcone VP Jr, Spiegel R Jr, et al. Hypnotic efficacy of temazepam: a long-term sleep laboratory evaluation. Br J Clin Pharmacol. 1979;8(1 Suppl):63S-8S

66 Roehrs T, Zorick F, Kaffeman M, Sicklesteel J, Roth T. Flurazepam for short-term treatment of complaints of insomnia. J Clin Pharmacol. 1982 Jul;22(7):290-6.

67 Roehrs T, Lamphere J, Paxton C, Wittig R, Zorick F, Roth T. Temazepam's efficacy in patients with sleep onset insomnia. Br J Clin Pharmacol. 1984 Jun;17(6):691-6

68 Scharf MB, Kales A, Bixler EO, Jacoby JA Schweitzer PK. Lorazepam-efficacy, side effects, and rebound phenomena. Clin Pharmacol Ther. 1982 Feb;31(2):175-9.

69 Walsh JK, Schweitzer PK, Parwatikar S. Effects of lorazepam and its withdrawal on sleep, performance, and subjective state. Clin Pharmacol Ther. 1983 Oct;34(4):496-500.

70 Chouinard G, Labonte A, Fontaine R, Annable L. New concepts in benzodiazepine therapy: rebound anxiety and new indications for the more potent benzodiazepines. Prog Neuropsychopharmacol Biol Psychiatry. 1983; 7(4-6):669-73

71 Morgan K, Oswald I. Anxiety caused by a short-life hypnotic. Br Med J (Clin Res Ed). 1982 Mar;284(6320):942.

72 Herman JB, Brotman AW, Rosenbaum JF. Rebound anxiety in panic disorder patients treated with shorter-acting benzodiazepines. J Clin Psychiatry. 1987 Oct;48 Suppl:22-8.

73 Chouinard G, Annable L, Fontaine R, Solyom L. Alprazolam in the treatment of generalized anxiety and panic disorders: a double-blind placebo-controlled study. Psychopharmacology (Berl). 1982;77(3):229-33.

74 Beaudry P, Fontaine R, Chouinard G, Annable L. Clonazepam in the treatment of patients with recurrent panic attacks. J Clin Psychiatry. 1986 Feb;47(2):83-5

75 Wolf B, Griffiths RR. Physical dependence on benzodiazepines: differences within the class. Drug Alcohol Depend. 1991 Dec;29(2):153-6.

76 Nardi AE, Machado S, Almada LF, Paes F, Silva $\mathrm{AC}$, Marques RJ, et al. Clonazepam for the treatment of panic disorder. Curr Drug Targets. 2013 Mar;14(3):353-64.

77 Starcevic V. The reappraisal of benzodiazepines in the treatment of anxiety and related disorders. Expert Rev Neurother. 2014 Nov; 14(11):1275-86.

78 Ashton C. Benzodiazepines: how they work \& how to withdraw. Newcastle: University of Newcastle; 2001

79 Voshaar RC, Couvée JE, van Balkom AJ, Mulder PG, Zitman FG. Strategies for discontinuing long-term benzodiazepine use: metaanalysis. Br J Psychiatry. 2006 Sep;189(3): 213-20. 
80 Murphy SM, Tyrer P. A double-blind comparison of the effects of gradual withdrawal of lorazepam, diazepam and bromazepam in benzodiazepine dependence. Br J Psychiatry. 1991 Apr;158(4):511-6.

81 Voshaar RC, Gorgels WJ, Mol AJ, van Balkom $\mathrm{AJ}$, van de Lisdonk $\mathrm{EH}$, Breteler $\mathrm{MH}$, et al. Tapering off long-term benzodiazepine use with or without group cognitive-behavioural therapy: three-condition, randomised controlled trial. Br J Psychiatry. 2003 Jun;182(6): 498-504.

82 Gosselin P, Ladouceur R, Morin CM, Dugas MJ, Baillargeon L. Benzodiazepine discontinuation among adults with GAD: A randomized trial of cognitive-behavioral therapy. J Consult Clin Psychol. 2006 Oct;74(5):908-19.

83 Baillargeon L, Landreville P, Verreault R, Beauchemin JP, Grégoire JP, Morin CM. Discontinuation of benzodiazepines among older insomniac adults treated with cognitivebehavioural therapy combined with gradual tapering: a randomized trial. CMAJ. 2003 Nov;169(10):1015-20.

84 Greenblatt DJ, Harmatz JS, Zinny MA, Shader RI. Effect of gradual withdrawal on the rebound sleep disorder after discontinuation of triazolam. N Engl J Med. 1987 Sep;317(12): $722-8$.

85 Roehrs T, Merlotti L, Zorick F, Roth T. Rebound insomnia in normals and patients with insomnia after abrupt and tapered discontinuation. Psychopharmacology (Berl). 1992; 108(1-2):67-71.

86 Otto MW, Pollack MH, Sachs GS, Reiter SR, Meltzer-Brody S, Rosenbaum JF. Discontinuation of benzodiazepine treatment: efficacy of cognitive-behavioral therapy for patients with panic disorder. Am J Psychiatry. 1993 Oct;150(10):1485-90.

87 Fava GA, Grandi S, Belluardo P, Savron G, Raffi AR, Conti S, et al. Benzodiazepines and anxiety sensitivity in panic disorder. Prog Neuropsychopharmacol Biol Psychiatry. 1994 Nov;18(7):1163-8.

88 Otto MW, McHugh RK, Simon NM, Farach FJ, Worthington JJ, Pollack MH. Efficacy of CBT for benzodiazepine discontinuation in patients with panic disorder: further evaluation. Behav Res Ther. 2010 Aug;48(8):720-7.

89 Jha MK, Rush AJ, Trivedi MH. When discontinuing SSRI antidepressants is a challenge: management tips. Am J Psychiatry. 2018 Dec; 175(12):1176-84.

90 Kramer JC, Klein DF, Fink M. Withdrawal symptoms following dicontinuation of imipramine therapy. Am J Psychiatry. 1961 Dec; 118(6):549-50

91 Jones BD, Steinberg S, Chouinard G. Fast-cycling bipolar disorder induced by withdrawal from long-term treatment with a tricyclic antidepressant. Am J Psychiatry. 1984 Jan; 141(1):108-9.

92 Dilsaver SC, Greden JF. Antidepressant withdrawal-induced activation (hypomania and mania): mechanism and theoretical significance. Brain Res. 1984 Mar;319(1):29-48.
93 Dilsaver SC. Antidepressant withdrawal syndromes: phenomenology and pathophysiology. Acta Psychiatr Scand. 1989 Feb; 79(2):113-7.

94 Dilsaver SC. Withdrawal phenomena associated with antidepressant and antipsychotic agents. Drug Saf. 1994 Feb;10(2):103-14.

95 Swann AC, Petty F, Bowden CL, Dilsaver SC, Calabrese JR, Morris DD. Mania: gender, transmitter function, and response to treatment. Psychiatry Res. 1999 Oct;88(1): $55-61$.

96 Boisvert D, Chouinard G. Rebound cardiac arrhythmia after withdrawal from imipramine: a case report. Am J Psychiatry. 1981 Jul;138(7):985-6.

97 Haddad PM. Antidepressant discontinuation syndromes. Drug Saf. 2001;24(3):18397.

98 Otani K, Tanaka O, Kaneko S, Ishida M, Yasui N, Fukushima Y. Mechanisms of the development of trazodone withdrawal symptoms. Int Clin Psychopharmacol. 1994;9(2): 131-3.

99 Menza MA. Withdrawal syndrome in a depressed patient treated with trazodone. Am J Psychiatry. 1986 Sep;143(9):1195.

100 Peabody CA. Trazodone withdrawal and formication. J Clin Psychiatry. 1987 Sep; 48(9):385.

101 Theilman SB, Christenbury MM. Hypomania following withdrawal of trazodone. Am J Psychiatry. 1986 Nov;143(11):1482-3.

102 Cosci F. Withdrawal symptoms after discontinuation of a noradrenergic and specific serotonergic antidepressant: A case report and review of the literature. Pers Med Psych. 2017;1-2:81-4.

103 De Leo D, Dalla Barba G, Zanchin G. Seizures following the withdrawal of long-term treatment with mianserin. Ital J Neurol Sci. 1988 Apr;9(2):167-9.

104 Kuniyoshi M, Arikawa K, Miura C, Inanaga K. Panic anxiety after abrupt discontinuation of mianserin. Jpn J Psychiatry Neurol. 1989 Jun;43(2):155-9.

105 Wang HY, Chou WJ, Huang TY, Hung CF. Acute dystonia resulting from abrupt bupropion discontinuation. Prog Neuropsychopharmacol Biol Psychiatry. 2007 Apr; 31(3):766-8.

106 Goodwin GM, Emsley R, Rembry S, Rouillon F; Agomelatine Study Group. Agomelatine prevents relapse in patients with major depressive disorder without evidence of a discontinuation syndrome: a 24 -week randomized, double-blind, placebo-controlled trial. J Clin Psychiatry. 2009 Aug;70(8): 1128-37.

107 Stein DJ, Ahokas A, Albarran C, Olivier V, Allgulander C. Agomelatine prevents relapse in generalized anxiety disorder: a 6-month randomized, double-blind, placebo-controlled discontinuation study. J Clin Psychiatry. 2012 Jul;73(7):1002-8.
108 Montgomery SA, Kennedy SH, Burrows GD, Lejoyeux M, Hindmarch I. Absence of discontinuation symptoms with agomelatine and occurrence of discontinuation symptoms with paroxetine: a randomized, double-blind, placebo-controlled discontinuation study. Int Clin Psychopharmacol. 2004 Sep;19(5):271-80.

109 Dubovsky SL. What Is New about New Antidepressants? Psychother Psychosom. 2018. 87(3):129-39.

110 Zajecka J, Tracy KA, Mitchell S. Discontinuation symptoms after treatment with serotonin reuptake inhibitors: a literature review. J Clin Psychiatry. 1997 Jul;58(7):291-7.

111 Rosenbaum JF, Fava M, Hoog SL, Ascroft RC, Krebs WB. Selective serotonin reuptake inhibitor discontinuation syndrome: a randomized clinical trial. Biol Psychiatry. 1998 Jul;44(2):77-87.

112 Belaise C, Gatti A, Chouinard VA, Chouinard G. Patient online report of selective serotonin reuptake inhibitor-induced persistent postwithdrawal anxiety and mood disorders. Psychother Psychosom. 2012;81(6): 386-8.

113 Michelson D, Fava M, Amsterdam J, Apter $\mathrm{J}$, Londborg P, Tamura R, et al. Interruption of selective serotonin reuptake inhibitor treatment. Double-blind, placebo-controlled trial. Br J Psychiatry. 2000 Apr; 176(4):363-8

114 Chouinard G, Saxena B, Bélanger MC, Ravindran $\mathrm{A}, \mathrm{Bakish} \mathrm{D}$, Beauclair $\mathrm{L}$, et al. A Canadian multicenter, double-blind study of paroxetine and fluoxetine in major depressive disorder. J Affect Disord. 1999 Jul;54(12):39-48.

115 Allgulander C, Hackett D, Salinas E. Venlafaxine extended release (ER) in the treatment of generalised anxiety disorder: twenty-four-week placebo-controlled dose-ranging study. Br J Psychiatry. 2001 Jul;179(1): 15-22.

116 Dallal A, Chouinard G. Withdrawal and rebound symptoms associated with abrupt discontinuation of venlafaxine. J Clin Psychopharmacol. 1998 Aug;18(4):343-4.

117 Shoenberger D. Discontinuing paroxetine: a personal account. Psychother Psychosom. 2002 Jul-Aug;71(4):237-8.

118 Belaise C, Gatti A, Chouinard VA, Chouinard G. Persistent postwithdrawal disorders induced by paroxetine, a selective serotonin reuptake inhibitor, and treated with specific cognitive behavioral therapy. Psychother Psychosom. 2014;83(4):247-8.

119 Stockmann T, Odegbaro D, Timimi S, Moncrieff J. SSRI and SNRI withdrawal symptoms reported on an internet forum. Int Risk Saf Med. 2018;29(3-4):175-80.

120 Boyd IW. Venlafaxine withdrawal reactions. Med J Aust. 1998 Jul;169(2):91-2.

121 Khazaal Y. Mania after venlafaxine withdrawal in a patient with generalized anxiety disorder. Ann Pharmacother. 2007 Feb; 41(2):359-60. 
122 Clewes J. A case report of onset of tinnitus following discontinuation of antidepressant and a review of the literature. Prim Care Companion CNS Disord. 2012; 14(1):pii:PCC.11br01218.

123 Hou YC, Lai CH. Long-term duloxetine withdrawal syndrome and management in a depressed patient. J Neuropsychiatry Clin Neurosci. 2014;26(1):E4.

124 Csoka AB, Shipko S. Persistent sexual side effects after SSRI discontinuation. Psychother Psychosom. 2006;75(3):187-8.

125 Bahrick A. Post SSRI Sexual Dysfunction. ASAP Tablet. 2006;7(3):10-1.

126 Bahrick A. Persistence of sexual dysfunction side effects after discontinuation of antidepressant medications: emerging evidence. Open Psychol J. 2008;1(1):42-50.

127 Bala A, Nguyen HM, Hellstrom WJ. PostSSRI Sexual Dysfunction: A Literature Review. Sex Med Rev. 2018 Jan;6(1):29-34

128 Healy D, Le Noury J, Mangin D. Enduring sexual dysfunction after treatment with antidepressants, $5 a$-reductase inhibitors and isotretinoin: 300 cases. Int J Risk Saf Med. 2018;29(3-4):125-34.

129 Patacchini A, Cosci F. A paradigmatic case of Post Selective serotonin reuptake inhibitors Sexual Dysfunction or withdrawal after discontinuation of Selective Serotonin Reuptake Inhibitors? J Clin Psychopharmacol. 2020 Jan/Feb;40(1):93-5.

130 Andrade C. Antidepressant-withdrawal mania:a critical review and synthesis of the literature. J Clin Psychiatry. 2004 Jul;65(7): 987-93.

131 Horowitz MA, Taylor D. Tapering of SSRI treatment to mitigate withdrawal symptoms. Lancet Psychiatry. 2019 Jun;6(6):53846.

132 Ruhe HG, Horikx A, van Avendonk MJ, Groeneweg BF, Woutersen-Koch H; Discontinuation of Antidepressants Taskforce. Tapering of SSRI treatment to mitigate withdrawal symptoms. Lancet Psychiatry. 2019 Jul;6(7):561-2.

133 Scholten WD, Batelaan NM, van Oppen P, Smit JH, Hoogendoorn AW, van Megen HJ, et al. The efficacy of a group CBT relapse prevention program for remitted anxiety disorder pateints who discontinue antidepressant medication: a randomized controlled trial. Psychother Psychosom. 2018; 87(4):240-2.

134 Esketamine nasal spray (Spravato) for treatment-resistant depression. Med Lett Drugs Ther. 2019 Apr;61(1569):54-7.

135 Witkin JM. mGlu2/3 receptor antagonism: A mechanism to induce rapid antidepressant effects without ketamine-associated side-effects. Pharmacol Biochem Behav. 2020 Mar; 190:172854.

136 Kamaya H, Krishna PR. Ketamine addiction. Anesthesiology. 1987 Nov;67(5):861-2.

137 Hurt PH, Ritchie EC. A case of ketamine dependence. Am J Psychiatry. 1994 May; 151(5):779.
138 Jansen KL, Darracot-Cankovic R. The nonmedical use of ketamine, part two: A review of problem use and dependence. J Psychoactive Drugs. 2001 Apr-Jun;33(2):151-8.

139 Pal HR, Berry N, Kumar R, Ray R. Ketamine dependence. Anaesth Intensive Care. 2002 Jun;30(3):382-4.

140 Caddy C, Amit BH, McCloud TL, Rendell JM, Furukawa TA, McShane R, et al. Ketamine and other glutamate receptor modulators for depression in adults. Cochrane Database Syst Rev. 2015 Sep;(9):CD011612.

141 Zhu W, Ding Z, Zhang Y, Shi J, Hashimoto $\mathrm{K}, \mathrm{Lu}$ L. Risks associated with misuse of ketamine as a rapid-acting antidepressant. Neurosci Bull. 2016 Dec;32(6):557-64.

142 Newport DJ, Schatzberg AF, Nemeroff CB. Whither ketamine as an antidepressant: pan $\neg$ acea or toxin? Depress Anxiety. 2016 Aug;33(8):685-8.

143 FDA Members of the Psychopharmacologic Drugs Advisory Committee (PDAC) and Drug Safety and Risk Management. (DSARM) Advisory Committee (2019). FDA Briefing Document Psychopharmacologic Drugs Advisory Committee (PDAC) and Drug Safety and Risk Management (DSaRM). [Accessed April 2019]. Available from: https://www.fda.gov/media/121376/ download.

144 Kim J, Farchione T, Potter A, Chen Q, Temple R. Esketamine for treatment-resistant depression - first FDA-approved antidepressant in a new class. N Engl J Med. 2019 Jul;381(1):1-4.

145 Lim DK. Ketamine associated psychedelic effects and dependence. Singapore Med J. 2003 Jan;44(1):31-4.

146 Critchlow DG. A case of ketamine dependence with discontinuation symptoms. Addiction. 2006 Aug;101(8):1212-3.

147 Chen WY, Huang MC, Lin SK. Gender differences in subjective discontinuation symptoms associated with ketamine use. Subst Abuse Treat Prev Policy. 2014 Sep; 9(1):39.

148 Nemeroff CB. Ketamine: quo Vadis? Am J Psychiatry. 2018 Apr;175(4):297-9.

149 Blendon RJ, Benson JM. The Public and the Opioid-Abuse Epidemic. N Engl J Med. 2018 Feb;378(5):407-11.

150 Chouinard G. New nomenclature for druginduced movement disorders including tardive dyskinesia. J Clin Psychiatry. 2004; 65(Suppl 9):9-15.

151 Chouinard G, Annable L, Ross-Chouinard A, Nestoros JN. Factors related to tardive dyskinesia. Am J Psychiatry. 1979 Jan; 136(1):79-82.

152 Chouinard G, Miller R. A rating scale for psychotic symptoms (RSPS) part I: theoretical principles and subscale 1: perception symptoms (illusions and hallucinations). Schizophr Res. 1999 Aug;38(2-3):101-22.
153 Chouinard G, Miller R. A rating scale for psychotic symptoms (RSPS): part II: subscale 2: distraction symptoms (catatonia and passivity experiences subscale 3: delusions and semi-structured interview (SSCI-RSPS) Schizophr Res. 1999 Aug;38(2-3):123-50.

154 Ekblom B, Eriksson K, Lindström LH. Supersensitivity psychosis in schizophrenic patients after sudden clozapine withdrawal. Psychopharmacology (Berl). 1984;83(3):293-4.

155 Seeman P, Tallerico T. Rapid release of antipsychotic drugs from dopamine D2 receptors: an explanation for low receptor occupancy and early clinical relapse upon withdrawal of clozapine or quetiapine. Am J Psychiatry. 1999 Jun;156(6):876-84.

156 Moncrieff J. Does antipsychotic withdrawal provoke psychosis? Review of the literature on rapid onset psychosis (supersensitivity psychosis) and withdrawal-related relapse. Acta Psychiatr Scand. 2006 Jul;114(1):3-13.

157 Margolese HC, Chouinard G, Beauclair L, Bélanger MC. Therapeutic tolerance and rebound psychosis during quetiapine maintenance monotherapy in patients with schizophrenia and schizoaffective disorder. J Clin Psychopharmacol. 2002 Aug;22(4):347-52.

158 Kimura H, Kanahara N, Komatsu N, Ishige M, Muneoka K, Yoshimura M, et al. A prospective comparative study of risperidone long-acting injectable for treatment-resistant schizophrenia with dopamine supersensitivity psychosis. Schizophr Res. 2014 May;155(1-3):52-8.

159 Takase M, Kanahara N, Oda Y, Kimura H, Watanabe H, Iyo M. Dopamine supersensitivity psychosis and dopamine partial agonist: a retrospective survey of failure of switching to aripiprazole in schizophrenia. J Psychopharmacol. 2015 Apr;29(4):383-9.

160 Suzuki T, Kanahara N, Yamanaka H, Takase M, Kimura H, Watanabe H, et al. Dopamine supersensitivity psychosis as a pivotal factor in treatment-resistant schizophrenia. Psychiatry Res. 2015 Jun;227(2-3):278-82.

161 Markowitz JS, Brown CS, Moore TR. Atypical antipsychotics. Part I: Pharmacology, pharmacokinetics, and efficacy. Ann Pharmacother. 1999 Jan;33(1):73-85.

162 Kapur S, Seeman P. Does fast dissociation from the dopamine $\mathrm{d}(2)$ receptor explain the action of atypical antipsychotics?: A new hypothesis. Am J Psychiatry. 2001 Mar;158(3): 360-9.

163 Bandelow B, Chouinard G, Bobes J, Ahokas A, Eggens I, Liu S, et al. Extended-release quetiapine fumarate (quetiapine XR): a once-daily monotherapy effective in generalized anxiety disorder. Data from a randomized, double-blind, placebo- and activecontrolled study. Int J Neuropsychopharmacol. 2010 Apr;13(3):305-20.

164 Chouinard G, Jones BD. Early onset of tardive dyskinesia: case report. Am J Psychiatry. 1979 Oct;136(10):1323-4. 
165 Chouinard G, Boisvert D, Bradwejn J. Tardive dyskinesia in a nonpsychiatric patient due to short-term use of a neuroleptic/anticholinergic combination drug. Can Med Assoc J. 1982 Apr;126(7):821-2.

166 Lee LH, Choi C, Collier AC, Barr AM, Honer WG, Procyshyn RM. The Pharmacokinetics of Second-Generation Long-Acting Injectable Antipsychotics: Limitations of Monograph Values. CNS Drugs. 2015 Dec; 29(12):975-83.

167 Kimura H, Kanahara N, Sasaki T, Komatsu $\mathrm{N}$, Ishige $\mathrm{M}$, Muneoka $\mathrm{K}$, et al. Risperidone long-acting injectable in the treatment of treatment-resistant schizophrenia with dopamine supersensitivity psychosis: results of a 2-year prospective study, including an additional 1-year follow-up. J Psychopharmacol. 2016 Aug;30(8):795-802

168 Christensen AV, Fjalland B, Nielsen IM. On the supersensitivity of dopamine receptors, induced by neuroleptics. Psychopharmacology (Berl). 1976 Jul;48(1):1-6.

169 Fallon P, Dursun SM. A naturalistic controlled study of relapsing schizophrenic patients with tardive dyskinesia and supersensitivity psychosis. J Psychopharmacol. 2011 Jun;25(6):755-62.

170 Fallon P, Dursun S, Deakin B. Drug-induced supersensitivity psychosis revisited: characteristics of relapse in treatment-compliant patients. Ther Adv Psychopharmacol. 2012 Feb;2(1):13-22.

171 Chouinard G, Beauclair L, Bélanger MC. Gabapentin: long-term antianxiety and hypnotic effects in psychiatric patients with comorbid anxiety-related disorders. Can J Psychiatry. 1998 Apr;43(3):305.

172 Goldstein J, Macfadden W. Reply to article by Margolese and associates on tolerance and rebound during maintenance with quetiapine. J Clin Psychopharmacol. 2004 Feb; 24(1):102-3.

173 Schou M. Is there a lithium withdrawal syndrome? An examination of the evidence. $\mathrm{Br}$ J Psychiatry. 1993 Oct;163(4):514-8.

174 Balon R, Yeragani VK, Pohl RB, Gershon S Lithium discontinuation: withdrawal or relapse? Compr Psychiatry. 1988 May-Jun; 29(3):330-4

175 Christodoulou GN, Lykouras EP. Abrupt lithium discontinuation in manic-depressive patients. Acta Psychiatr Scand. 1982 May;65(5):310-4.

176 Butler M, Urosevic S, Desai P, Sponheim SR, Popp J, Nelson VA, et al. Comparative Effectiveness Review, No. 208. Treatment for Bipolar Disorder in Adults: A Systematic Review. Rockville (MD): Agency for Healthcare Research and Quality (US) Publication No. 18-EHC012-EF; 2018.

177 Chen MJ, Zhang WJ, Guo ZL, Zhang WH, Chai Y, Li YW. Withdrawal reaction of carbamazepine after neurovascular decompression for trigeminal neuralgia: a preliminary study. J Neurol Sci. 2014 Mar;338(1-2):43-5.
178 Duncan JS, Shorvon SD, Trimble MR. Withdrawal symptoms from phenytoin, carbamazepine and sodium valproate. J Neurol Neurosurg Psychiatry. 1988 Jul;51(7):924-8.

179 Gelisse P, Kissani N, Crespel A, Jafari H, Baldy-Moulinier M. Is there a lamotrigine withdrawal syndrome? Acta Neurol Scand. 2002 Mar; 105(3):232-4.

180 Frey LC, Strom LA, Shrestha A, Spitz MC. End-of-dose emergent psychopathology in ambulatory patients with epilepsy on stabledose lamotrigine monotherapy: a case series of six patients. Epilepsy Behav. 2009 Aug; 15(4):521-3.

181 Cosci F, Guidi J, Balon R, Fava GA. Clinical Methodology Matters in Epidemiology: Not All Benzodiazepines Are the Same. Psychother Psychosom. 2015;84(5):262-4.

182 American Psychiatric Association. Diagnostic and statistical manual of mental disorders. 5th ed. Arlington (VA): American Psychiatric Publishing; 2013.

183 Balon R, Silberman EK, Starcevic V, Cosci F, Freire RC, Nardi AE, et al. Benzodiazepines, antidepressants and addiction: A plea for conceptual rigor and consistency. J Psychopharmacol. 2019 Nov;33(11):1467-70.

184 Dell'Osso B, Albert U, Atti AR, Carmassi C, Carrà $\mathrm{G}$, Cosci $\mathrm{F}$, et al. Bridging the gap between education and appropriate use of benzodiazepines in psychiatric clinical practice. Neuropsychiatr Dis Treat. 2015 Jul;11: 1885-909.

185 Batelaan NM, Bosman RC, Mintingh A, Scholten WD, Huijbregts KM, van Balkom AJLM. Risk of relapse after antidepressant discontinuation in anxiety disorders, obsessive-compulsive disorder, and post-traumatic stress disorder: systematic review and meta-analysis of relapse prevention trials. BMJ. 2017 Sep;358:33927.

186 Offidani E, Guidi J, Tomba E, Fava GA. Efficacy and tolerability of benzodiazepines versus antidepressants in anxiety disorders: a systematic review and meta-analysis. Psychother Psychosom. 2013;82(6):355-62.

187 Balon R, Chouinard G, Cosci F, Dubovsky SL, Fava GA, Freire RC, et al. International Task Force on Benzodiazepines. Psychother Psychosom. 2018;87(4):193-4.

188 DiMascio A, Shader RI. Behavioral toxicity of psychotropic drugs. I. Definition. II. Toxic effects on psychomotor functions. Conn Med. 1968 Aug;32(8):617-20.

189 DiMascio A, Giller DR, Shader RI. Behavioral toxicity of psychotropic drugs. 3. Effects on perceptual and cognitive functions. IV. Effects on emotional (mood) states. Conn Med. 1968 Oct;32(10):771-5.

190 DiMascio A, Shader RI, Harmatz GS. Behavioral toxicity of psychotropic drugs. V. Effects on gross behavior patterns. Conn Med. 1969 Apr;33(4):279-81.

191 Fava GA. Do antidepressant and antianxiety drugs increase chronicity in affective disorders? Psychother Psychosom. 1994;61(3-4): 125-31.
192 Mancuso CE, Tanzi MG, Gabay M. Paradoxical reactions to benzodiazepines: literature review and treatment options. Pharmacotherapy. 2004 Sep;24(9):1177-85.

193 Hindmarch I. Cognitive toxicity of pharmacotherapeutic agents used in social anxiety disorder. Int J Clin Pract. 2009 Jul;63(7): 1085-94.

194 Perl M, Hall RC, Gardner ER. Behavioral toxicity of psychiatric drugs. In: Hall RC, editor. Psychiatric presentations of medical illness. New York: Spectrum Publications; 1980. pp. 311-36.

195 Rothschild AJ, Raskin J, Wang CN, Marangell $L B$, Fava $M$. The relationship between change in apathy and changes in cognition and functional outcomes in currently non-depressed SSRI-treated patients with major depressive disorder. Compr Psychiatry. 2014 Jan;55(1):1-10.

196 Van Putten T, Marder SR. Behavioral toxicity of antipsychotic drugs. J Clin Psychiatry. 1987 Sep;48 Suppl:13-9.

197 Lazarou J, Pomeranz BH, Corey PN. Incidence of adverse drug reactions in hospitalized patients: a meta-analysis of prospective studies. JAMA. 1998 Apr;279(15):1200-5.

198 Enlund H, Vainio K, Wallenius S, Poston JW. Adverse drug effects and the need for drug information. Med Care. 1991 Jun; 29(6):558-64.

199 Thornlow DK, Anderson R, Oddone E. Cascade iatrogenesis: factors leading to the development of adverse events in hospitalized older adults. Int J Nurs Stud. 2009 Nov; 46(11):1528-35.

200 Fava GA, Tomba E, Tossani E. Innovative trends in the design of therapeutic trials in psychopharmacology and psychotherapy. Prog Neuropsychopharmacol Biol Psychiatry. 2013 Jan;40:306-11.

201 Fava GA, Cosci F. Addressing Clinical Challenges of Antidepressant Discontinuation. Am J Psychiatry. 2019 Jun;176(6):487-8.

202 Offidani E, Fava GA, Sonino N. Iatrogenic comorbidity in childhood and adolescence: new insights from the use of antidepressant drugs. CNS Drugs. 2014 Sep;28(9):769-74.

203 Fava GA. Can long-term treatment with antidepressant drugs worsen the course of depression? J Clin Psychiatry. 2003 Feb;64(2): 123-33.

204 Fava GA, Offidani E. The mechanisms of tolerance in antidepressant action. Prog Neuropsychopharmacol Biol Psychiatry. 2011 Aug;35(7):1593-602.

205 Reed GM, First MB, Kogan CS, Hyman SE, Gureje $\mathrm{O}$, Gaebel W, et al. Innovations and changes in the ICD-11 classification of mental, behavioural and neurodevelopmental disorders. World Psychiatry. 2019 Feb; 18(1):3-19.

206 Fava GA, Tomba E, Brakemeier EL, Carrozzino D, Cosci F, Eöry A, et al. Mental Pain as a Transdiagnostic Patient-Reported Outcome Measure. Psychother Psychosom. 2019;88(6):341-9. 
207 Guidi J, Piolanti A, Gostoli S, Schamong I, Brakemeier EL. Mental Pain and Euthymia as Transdiagnostic Clinimetric Indices in Primary Care. Psychother Psychosom. 2019; 88(4):252-3.

208 Svicher A, Romanazzo S, De Cesaris F, Benemei S, Geppetti P, Cosci F. Mental Pain Questionnaire: an item response theory analysis. J Affect Disord. 2019 Apr;249:22633.

209 Fava GA, Guidi J, Rafanelli C, Rickels K. The clinical inadequacy of the placebo model and the development of an alternative conceptual framework. Psychother Psychosom. 2017;86(6):332-40.

210 Cohen D, Recalt A. Discontinuing Psychotropic Drugs from Participants in Randomized Controlled Trials: A Systematic Review. Psychother Psychosom. 2019;88(2):96-104.

211 Récalt AM, Cohen D. Withdrawal confounding in randomized controlled trials of antipsyhotic, antidepressant, and stimulant drugs, 2000-2017. Psychother Psychosom. 2019;88(2):105-13.
212 Baldessarini RJ, Tondo L. Effects of Treatment Discontinuation in Clinical Psychopharmacology. Psychother Psychosom. 2019;88(2):65-70.

213 Baldessarini RJ. Chemotherapy in Psychiatry. 3rd ed. New York: Springer Press; 2013. https://doi.org/10.1007/978-1-4614-3710-9.

214 Baldessarini RJ, Lau WK, Sim J, Sum MY, Sim K. Duration of initial antidepressant treatment and subsequent relapse of major depression. J Clin Psychopharmacol. 2015 Feb;35(1):75-6.

215 Sim K, Lau WK, Sim J, Sum MY, Baldessarini RJ. Prevention of relapse and recurrence in adults with major depressive disorder: systematic review and meta-analyses of controlled trials. Int J Neuropsychopharmacol. 2015 Jul;19(2):1-13.

216 Zito MJ, Safer DJ, Craig TJ. Pharmacoepidemiology of psychiatric disorders. In: Hartzema AG, Tilson HH, Chan KA, editors. Pharmacoepidemiology and therapeutic risk management. Cincinnati: Harvey Whitney Books; 2008. pp. 817-54.

217 Zito JM. High-dose benzodiazepine use among long-term users: when will we ever learn? Psychother Psychosom. 2015;84(5): 259-61.
218 Gnjidic D, Tinetti M, Allore HG. Assessing medication burden and polypharmacy: finding the perfect measure. Expert Rev Clin Pharmacol. 2017 Apr;10(4):345-7.

219 Ghaemi SN. Polypharmacy in Psychiatry. New York: Dekker; 2002.

220 Cosci F, Chouinard G, Chouinard VA, Fava GA. The Diagnostic clinical Interview for Drug Withdrawal 1 (DID-W1) - New Symptoms of Selective Serotonin Reuptake Inhibitors (SSRI) or Serotonin Norepinephrine Reuptake Inhibitors (SNRI): inter-rater reliability. Riv Psichiatr. 2018 Mar-Apr; 53(2):95-9.

221 Fava GA, Tomba E, Bech P. Clinical Pharmacopsychology: Conceptual Foundations and Emerging Tasks. Psychother Psychosom. 2017;86(3):134-40.

222 Fava GA, Carrozzino D, Lindberg L, Tomba E. The Clinimetric Approach to Psychological Assessment: A Tribute to Per Bech, MD (1942-2018). Psychother Psychosom. 2018; 87(6):321-6. 